\title{
Asset allocation and derivatives
}

\author{
Martin B Haugh and Andrew W Lo ${ }^{1}$ \\ MIT Sloan School of Management and Operations Research Center, \\ 50 Memorial Drive, E52-432, Cambridge, MA 02142-1347, USA \\ E-mail: alo@mit.edu
}

Received 14 November 2000

\begin{abstract}
The fact that derivative securities are equivalent to specific dynamic trading strategies in complete markets suggests the possibility of constructing buy-and-hold portfolios of options that mimic certain dynamic investment policies, e.g. asset-allocation rules. We explore this possibility by solving the following problem: given an optimal dynamic investment policy, find a set of options at the start of the investment horizon which will come closest to the optimal dynamic investment policy. We solve this problem for several combinations of preferences, return dynamics and optimality criteria, and show that under certain conditions, a portfolio consisting of just a few options is an excellent substitute for considerably more complex dynamic investment policies.
\end{abstract}

\section{Introduction}

It is now well known that under certain conditions, complex financial instruments such as options and other derivative securities can be replicated by sophisticated dynamic trading strategies involving simpler securities such as stocks and bonds. This 'delta-hedging' strategy-for which Robert Merton and Myron Scholes shared the Nobel Memorial Prize in Economics in 1998-is largely responsible for the multitrillion-dollar derivatives industry and is now part of the standard toolkit of every derivatives dealer in the world.

The essence of delta-hedging is the ability to actively manage a portfolio continuously through time, and to do so in a 'self-financing' manner, i.e. no cash inflows or outflows after the initial investment, so that the portfolio's value tracks the value of the derivative security without error at each point in time, until the maturity date of the derivative. If such a portfolio strategy were possible, then the cost of implementing it must equal the price of the derivative, otherwise an arbitrage opportunity would exist. Black and Scholes (1973) and Merton (1973) used this argument to deduce the celebrated BlackScholes option-pricing formula, but an even more significant outcome of their research was the insight that there exists a correspondence between dynamic trading strategies over a period of time and complex securities at a single point in time.

In this paper, we consider the reverse implications of this correspondence by constructing an optimal portfolio of

1 Corresponding author. complex securities at a single point in time to mimic the properties of a dynamic trading strategy over a period of time. Specifically, we focus on dynamic investment policies, i.e. asset-allocation rules, that arise from standard dynamic optimization problems in which an investor maximizes the expected utility of his end-of-period wealth, and we pose the following problem: given an investor's optimal dynamic investment policy for two assets, stocks and bonds, construct a 'buy-and-hold' portfolio-a portfolio that involves no trading once it is established-of stocks, bonds and options at the start of the investment horizon that will come closest to the optimal dynamic policy. By defining 'closest' in three distinct ways-expected utility, mean-squared error of terminal wealth and utility-weighted mean-squared error of terminal wealth-we propose three sets of numerical algorithms for solving this problem in general, and characterize specific solutions for several sets of preferences (constant relative risk-aversion, constant absolute risk-aversion) and return dynamics (geometric Brownian motion, mean-reverting processes).

The optimal buy-and-hold problem is an interesting one for several reasons. First, it is widely acknowledged that the continuous-time framework in which most of modern finance has been developed is an approximation to reality-it is currently impossible to trade continuously, and even if it were possible, market frictions would render continuous trading infinitely costly. Consequently, any practical implementation 
of continuous-time asset-allocation policies invariably requires some discretization in which the investor's portfolio is rebalanced only a finite number of times, typically at equally spaced time intervals, with the number of intervals chosen so that the discrete asset-allocation policy 'approximates' the optimal continuous-time policy in some metric. However, Merton's (1973) insight suggests that it may be possible to approximate a continuous-time trading strategy in a different manner, i.e. by including a few well-chosen options in the portfolio at the outset and trading considerably less frequently. In particular, Merton (1995) observes that derivatives can be an effective substitute for dynamic open-market operations of central banks seeking to engage in interest-rate stabilization policies. Therefore, in the presence of transactions costs, derivative securities may be an efficient way to implement optimal dynamic investment policies ${ }^{2}$. Indeed, we find that under certain conditions, a buy-and-hold portfolio consisting of just a few options is an excellent substitute for considerably more complex dynamic investment policies.

Second, the approximation errors between the optimal dynamic policy and the buy-and-hold policy will reveal the importance of dynamic trading, the 'completeness' of financial markets, and the ability of investors to achieve certain financial goals in a cost-effective manner ${ }^{3}$. In particular, the conditions that guarantee dynamic completeness are nontrivial restrictions on market structure and price dynamics (see, for example, Duffie and Huang (1985)), hence there are situations in which exact replication is impossible. These instances of market incompleteness are often attributable to institutional rigidities and market frictions - transactions costs, periodic market closures and discreteness in trading opportunities and prices - and while the pricing of derivative securities can still be accomplished in some cases via equilibrium arguments ${ }^{4}$, this still leaves open the question of how expensive it is to achieve certain financial objectives, or how close one can come to those objectives for a given budget?

Finally, the optimal buy-and-hold portfolio can be used to develop a measure of the risks associated with the corresponding dynamic investment policy that the buy-andhold portfolio is designed to replicate. While there is general agreement in the financial community regarding the proper measurement of risk in a static context-the market beta

2 Taxes can be viewed as another type of transactions cost and the optimal buy-and-hold portfolio offers several additional advantages over the optimal dynamic investment policy for taxable investors.

3 Financial markets are said to be 'complete' (in the Arrow-Debreu sense) if it is possible to construct a portfolio of securities at a point in time which guarantees a specific payoff in a specific state of nature at some future date. The notion of 'dynamic completeness' is the natural extension of this idea to dynamic trading strategies. See Harrison and Kreps (1979) and Duffie and Huang (1985) for a more detailed discussion.

4 Examples of continuous-time incomplete-markets models include Breeden (1979), Duffie and Shafer (1985, 1986), Föllmer and Sonderman (1986), Duffie (1987) and He and Pearson (1991). Examples of discrete-time incomplete-markets models include Scheinkman and Weiss (1986), Aiyagari and Gertler (1991), Heaton and Lucas (1992, 1996), Weil (1992), Telmer (1993), Aiyagari (1994), Lucas (1994) and He and Modest (1995). Other aspects of pricing and hedging in incomplete markets have been considered by Magill and Quinzii (1996), Kallsen (1999), Kramkov and Schachermeyer (1999), Bertsimas et al (2000b), Goll and Rueschendorf (2000) and Schäl (2000). from the Capital Asset Pricing Model-there is no consensus regarding the proper measurement of risk for dynamic investment strategies. Market betas are notoriously unreliable in a multiperiod setting ${ }^{5}$, and other measures such as the Sharpe ratio, the Sortino ratio and maximum drawdown have been used to capture different risk exposures of dynamic investment strategies. By developing a correspondence between a dynamic investment strategy and a buy-and-hold portfolio, it may be possible to construct a more comprehensive set of risk measures for the dynamic strategy through the characteristics of the buy-and-hold portfolio and the approximation error.

In section 2 we provide a brief review of the strands of the asset allocation and derivatives pricing literature that are most relevant to our problem. We describe the buy-and-hold alternative to the standard asset-allocation problem in section 3 and propose three methods for solving it: maximization of expected utility, minimization of mean-squared error and a hybrid of the two (minimization of utility-weighted meansquared error). While the first approach is the most direct, it is also the most computationally intensive. The latter two approaches are simpler to implement, however, they do not maximize expected utility and as a result, the portfolios that they generate may be suboptimal. These issues are addressed in more detail in sections 4 and 5 where we implement the three methods for geometric Brownian motion, the Ornstein-Uhlenbeck process, and a bivariate linear diffusion process with a stochastic mean-reverting drift. Extensions, qualifications and other aspects of the optimal buy-and-hold portfolio are discussed in section 6 , and we conclude in section 7 .

\section{Literature review}

The literature on asset allocation is vast and addresses a broad set of issues, many that are beyond the scope of this paper's main focus ${ }^{6}$. Most studies that consider derivatives in the context of asset allocation use option-pricing methods to gauge the economic value of market-timing skills, e.g. Merton (1981), Henriksson and Merton (1981), and Evnine and Henriksson (1987). Carr et al (2000) solve the assetallocation problem in an economy where derivatives are required to complete the market. Carr and Madan (2000) consider a single-period model where agents are permitted to trade the stock, bond and European options with a continuum of strikes. Because of the inability to trade dynamically, options constitute a new asset class and the impact of beliefs and preferences on the agent's positions in the three asset classes is studied. In a general equilibrium framework, they derive conditions for mutual-fund separation where some of the separating funds are composed of derivative securities. None of these papers explores the possibility of substituting a simple buy-and-hold portfolio for a dynamic investment policy.

Three other strands of the literature are relevant to our paper: Merton's (1995) functional approach to understanding

5 See, for example, the short-put strategy described in Lo (2000).

6 See Sharpe (1987), Arnott and Fabozzi (1992) and Bodie et al (1999) for more detailed expositions of asset allocation. 
the dynamics of financial innovation ${ }^{7}$, the literature on dynamic portfolio choice with transactions costs, and the literature on option replication.

Among the many examples contained in Merton (1995) illustrating the importance of function in determining institutional structure is the example of the German government's issuance in 1990 of ten-year Schuldschein bonds with put-option provisions. Merton (1995) observes that the put provisions have the same effect as an interest-rate stabilization policy in which the government repurchases bonds when bond prices fall and sells bonds when bond prices rise. More importantly, Merton (1995) writes that '.. the put bonds function as the equivalent of a dynamic, 'open market', trading operation without any need for actual transactions'. This automatic stabilization policy is a 'proof of concept' for the possibility of substituting a buy-and-hold portfolio for a particular dynamic investment strategy, and the optimal buy-and-hold portfolio of section 3 may be viewed as a generalization of Merton's automatic stabilization policy to the asset-allocation problem.

Magill and Constantinides (1976) were among the first to point out that in the presence of transactions costs, trading occurs only at discrete points in time. More recent studies by Davis and Norman (1990), Aiyagari and Gertler (1991), Heaton and Lucas $(1992,1996)$ and He and Modest (1995) have contributed to the growing consensus that trading costs have a significant impact on investment performance and, therefore, investor behaviour. Despite the recent popularity of internet-based day-trading, it is now widely accepted that buyand-hold strategies such as indexation are difficult to beattransactions costs and management fees can quickly dissipate the value-added of many dynamic asset-allocation strategies.

The option-replication literature is relevant to our paper primarily because of the correspondence between a complex security and a dynamic trading strategy in simpler securities, an insight which gave rise to this literature. The classic references are Black and Scholes (1973), Merton (1973), Cox and Ross (1976), Harrison and Kreps (1979), Duffie and Huang (1985), and Huang (1985a, b). More recently, several studies have considered the option-replication problem directly, in some cases using mean-squared error as the objective function to be minimized $^{8}$, and in other cases with transactions costs 9 . In the latter set of studies, the existence of transactions costs induces discrete trading intervals, and the optimal replication problem is solved for some special cases, e.g. call and put options on stocks with geometric Brownian motion or constant-elasticityof-variance price dynamics, or for more general derivative securities under vector-Markov price processes.

We take these somewhat disparate literatures as our starting point. Merton's (1995) automatic stabilization policy illustrates the possibility of substituting a static buy-andhold portfolio for a specific dynamic trading strategy, i.e. an

\footnotetext{
7 See also, Bodie and Merton (1995) and Merton (1997).

8 See, for example, Duffie and Jackson (1990), Schweizer (1992, 1995, 1996), Schäl (1994), Delbaen and Schachermeyer (1996) and Bertsimas et al (2000a). 9 See Leland (1985), Hodges and Neuberger (1989), Bensaid et al (1992), Boyle and Vorst (1992), Davis et al (1993), Edirisinghe et al (1993), Henrotte (1993), Avellaneda and Paras (1994), Neuberger (1994), Whalley and Wilmott (1994), Grannan and Swindle (1996) and Toft (1996).
}

interest-rate stabilization policy. The fact that trading is costly implies that continuous asset-allocation is not feasible, and that alternatives to frequent trading are important to investors. The technology for replicating options is clearly well established, and a natural generalization of that technology is to construct portfolios of options that replicate more general dynamic trading strategies. We begin developing this generalization in the next section.

\section{The optimal buy-and-hold portfolio}

The asset-allocation problem has become one of the classic problems of modern finance, thanks to Samuelson's (1969) and Merton's (1969) pioneering studies over three decades ago. The simplest formulation-one without intermediate consumption - consists of an investor's objective to maximize the expected utility $\mathrm{E}\left[U\left(W_{T}\right)\right]$ of end-of-period wealth $W_{T}$ by allocating his wealth $W_{t}$ between two assets, a risky security (the 'stock') and a riskless security (the 'bond'), over some investment horizon $[0, T]$. The bond is assumed to yield a riskless instantaneous return of $r \mathrm{~d} t$ and with an initial market price of $\$ 1$, the bond price at any date $t$ is simply $\exp (r t)$. The stock price is denoted by $P_{t}$ and is typically assumed to satisfy an Itô stochastic differential equation:

$$
\mathrm{d} P_{t}=\mu\left(P_{t}, t\right) P_{t} \mathrm{~d} t+\sigma\left(P_{t}, t\right) P_{t} \mathrm{~d} B_{t}
$$

where $B_{t}$ is standard Brownian motion and $\mu\left(P_{t}, t\right)$ and $\sigma\left(P_{t}, t\right)$ satisfy certain regularity conditions that ensure the existence of a solution to (3.1). The standard asset-allocation problem is then:

$$
\operatorname{Max}_{\left\{\omega_{t}\right\}} \mathrm{E}\left[U\left(W_{T}\right)\right]
$$

subject to

$$
\mathrm{d} W_{t}=\left[r+\omega_{t}(\mu-r)\right] W_{t} \mathrm{~d} t+\omega_{t} W_{t} \sigma \mathrm{d} B_{t}
$$

where $\omega_{t}$ is the fraction of the investor's portfolio invested in the stock at time $t$ and (3.3) is the budget constraint that wealth $W_{t}$ must satisfy at all times $t \in[0, T]{ }^{10}$

Denote by $\left\{\omega_{t}^{*}\right\}$ the optimal dynamic investment policy, i.e. the solution to (3.2) and (3.3), and let $W_{T}^{*}$ denote the endof-period wealth generated by the optimal policy. The question we wish to answer in this paper is: how close can we come to this optimal policy with a buy-and-hold portfolio of stocks, bonds and options? We measure closeness in three ways: a direct approach in which we maximize the expected utility of the buy-and-hold portfolio, and two indirect approaches in which we minimize the mean-squared error and weighted mean-squared error between $W_{T}^{*}$ and the end-of-period wealth of the buy-and-hold portfolio. These three approaches are described in sections 3.1-3.3, respectively.

\subsection{Maximizing expected utility}

Our reformulation of the standard asset-allocation problem (3.2) and (3.3) contains only two modifications: (1) we allow the investor to include up to $n$ European call options in his

${ }^{10}$ See Merton (1992, chapter 5) for details. 
portfolio at date 0 which expire at date $T ;{ }^{11}$ and (2) we do not allow the investor to trade after setting up his initial portfolio of stocks, bonds and options. Specifically, denote by $D_{i}$ the date- $T$ payoff of a European call option with strike price equal to $k_{i}$, hence:

$$
D_{i}=\left(P_{T}-k_{i}\right)^{+} .
$$

Then the 'buy-and-hold' asset-allocation problem for the investor is given by:

$$
\operatorname{Max}_{\left\{a, b, c_{i}, k_{i}\right\}} \mathrm{E}\left[U\left(V_{T}\right)\right]
$$

subject to

$$
\begin{aligned}
& V_{T} \equiv a \exp (r T)+b P_{T}+c_{1} D_{1}+c_{2} D_{2}+\cdots+c_{n} D_{n} \\
& W_{0}=\exp (-r T) \mathrm{E}^{Q}\left[V_{T}\right]
\end{aligned}
$$

where $a$ and $b$ denote the investor's position in bonds and stock, and $c_{1}, \ldots, c_{n}$ the number of options with strike prices $k_{1}, \ldots, k_{n}$, respectively. Note that we use $V_{T}$ instead of $W_{T}$ to denote the investor's end-of-period wealth to emphasize the distinction between this case and the standard assetallocation problem in which stocks and bonds are the only assets considered and intermediate trading is allowed.

The budget constraint is given by (3.7), where $\mathrm{E}^{Q}[\cdot]$ is the expectation operator under the equivalent martingale measure $Q .{ }^{12}$ This constraint is highly nonlinear in the option strikes $\left\{k_{i}\right\}$, creating significant computational challenges for any optimizer. Moreover, for certain utility functions, it is necessary to impose solvency constraints to avoid bankruptcy, and such constraints add to the computational complexity of the problem.

For these reasons, our approach for solving (3.5)-(3.7) consists of two steps. In the first step, we assume that the strike prices $\left\{k_{i}\right\}$ are fixed, in which case (3.5)-(3.7) reduces to maximizing a concave objective function subject to linear constraints. Such a problem has a unique global optimum that is generally quite easy to find. This is done by discretizing the distribution of $P_{T}$ and solving the Karush-Kuhn-Tucker conditions which, in this case, are sufficient for an optimal solution $^{13}$. We will refer to this problem-where the strikes $\left\{k_{i}\right\}$ are fixed-as the 'subproblem'.

The second step involves determining the best set of strikes. We propose to solve this problem by specifying in advance a large number, $N \gg n$, of possible strikes where the $N$ strikes are chosen to be representative of the distribution of $P_{T}$. We then solve the subproblem for each of the $\left(\begin{array}{l}N \\ n\end{array}\right)$ possible combinations of options and select the best combination.

In selecting the set of $N$ strikes, we must ensure that their range spans a significant portion of the support of $P_{T}$. Therefore, the distribution of $P_{T}$ must be taken into account in specifying the strikes. Given a distribution for $P_{T}$, we select

\footnotetext{
${ }^{11}$ Without loss of generality, we focus exclusively on call options for expositional simplicity. Parallel results for put options can be easily derived via put-call parity (see, for example, Cox and Rubinstein (1985)).

${ }^{12}$ Note that specifying $Q$ yields pricing formulae for all the options contained in our optimal buy-and-hold portfolio since $\exp (-r T) \mathrm{E}^{Q}\left[D_{i}\right]$ is the date-0 price of option $i$. Therefore, option-pricing formulae are implicit in (3.7). For example, it is easy to verify that under geometric Brownian motion, $\exp (-r T) \mathrm{E}^{Q}\left[D_{i}\right]$ reduces to the celebrated Black-Scholes formula.

${ }^{13}$ See, for example, Bertsekas (1999).
}

an interval of its support and choose $N$ points-spaced either evenly (for simplicity) or according to the probability mass of the distribution of $P_{T}$ (for efficiency) — so that approximately 4 to 6 standard deviations of $P_{T}$ are contained within the interval.

In solving each subproblem, we discretize the distribution of $P_{T}$. This yields a straightforward nonlinear optimization problem with a concave objective function and linear constraints, which can be solved relatively quickly.

One subtlety arises for CRRA utility: the function is not defined for negative wealth. In such cases, the following $n+2$ solvency constraints must be imposed along with the budget constraint to ensure non-negative wealth:

$$
\begin{aligned}
0 & \leqslant a \exp (r T) \\
0 & \leqslant a \exp (r T)+b k_{1} \\
0 & \leqslant a \exp (r T)+\left(b+c_{1}\right) k_{2}-c_{1} k_{1} \\
& \vdots \\
0 & \leqslant a \exp (r T)+\left(b+c_{1}+\cdots+c_{n-1}\right) k_{n} \\
& -\left(c_{1} k_{1}+\cdots+c_{n-1} k_{n-1}\right) \\
0 & \leqslant b+c_{1}+\cdots+c_{n} \\
0 & \leqslant k_{1} \leqslant k_{2} \leqslant \cdots \leqslant k_{n} .
\end{aligned}
$$

\subsection{Minimizing mean-squared error}

In situations where the computational demands of the buyand-hold asset-allocation problem of section 3.1 are too great, a less demanding alternative is to use mean-squared error as the metric for measuring the closeness of the end-of-period wealth $V_{T}$ of the buy-and-hold portfolio of stocks, bonds, and options with the end-of-period wealth $W_{T}^{*}$ of the optimal portfolio. In addition, for dynamic investment policies that are not derived from maximization of expected utility, e.g. dollar-cost averaging, a mean-squared-error objective function may be appropriate. In this case, the buy-and-hold portfolio problem becomes:

$$
\operatorname{Min}_{\left\{a, b, c_{i}, k_{i}\right\}} \mathrm{E}\left[\left(W_{T}^{*}-V_{T}\right)^{2}\right]
$$

subject to

$$
V_{T} \equiv a \exp (r T)+b P_{T}+c_{1} D_{1}+c_{2} D_{2}+\cdots+c_{n} D_{n}
$$$$
W_{0}=\exp (-r T) \mathrm{E}^{Q}\left[V_{T}\right]
$$

If $W_{T}^{*}$ depends only on the terminal stock price $P_{T}$ and not on any of its path $\left\{P_{t}\right\}$-as is the case when $\left\{P_{t}\right\}$ follows a geometric Brownian motion and $W_{T}^{*}$ is the end-of-period wealth from an optimization of an investor's expected utilityit can be shown that $V_{T}$ can be made arbitrarily close to $W_{T}^{*}$ in mean-square as the number of options $n$ in the buy-and-hold portfolio increases without bound. If we do not impose any additional constraints beyond the budget constraint (such as the solvency constraints (3.8) of section 3.1), the corresponding subproblems for (3.9)-(3.11) can be solved very quickly, and the first-order conditions, which are necessary and sufficient, merely amount to solving a series of linear equations.

Specifically, the subproblem associated with (3.9)-(3.11) consists of selecting portfolio weights for stocks, bonds and options to minimize the mean-squared error between $W_{T}^{*}$ and $V_{T}$, holding fixed the strike prices $\left\{k_{i}\right\}$ of the $n$ options available 
to the investor. It is clear from (3.9)-(3.11) that for fixed strike prices, the objective function is convex so the first-order conditions are sufficient to characterize an optimal solution. These conditions may be written as

$\left[\begin{array}{llllll}\exp (r T) & \mathrm{E}\left[P_{T}\right] & \mathrm{E}\left[D_{1}\right] & \cdots & \mathrm{E}\left[D_{n}\right] & \exp (-r T) \\ \exp (r T) \mathrm{E}\left[P_{T}\right] & \mathrm{E}\left[P_{T}^{2}\right] & \mathrm{E}\left[D_{1} P_{T}\right] & \cdots & \mathrm{E}\left[D_{n} P_{T}\right] & P_{0} \\ \exp (r T) \mathrm{E}\left[D_{1}\right] & \mathrm{E}\left[P_{T} D_{1}\right] & \mathrm{E}\left[D_{1}^{2}\right] & \cdots & \mathrm{E}\left[D_{n} D_{1}\right] & \exp (-r T) \mathrm{E}^{Q}\left[D_{1}\right] \\ \exp (r T) \mathrm{E}\left[D_{2}\right] & \mathrm{E}\left[P_{T} D_{2}\right] & \mathrm{E}\left[D_{1} D_{2}\right] & \cdots & \mathrm{E}\left[D_{n} D_{2}\right] & \exp (-r T) \mathrm{E}{ }^{Q}\left[D_{2}\right] \\ \vdots & \vdots & \vdots & \cdots & \vdots & \vdots \\ \exp (r T) \mathrm{E}\left[D_{n}\right] & \mathrm{E}\left[P_{T} D_{n}\right] & \mathrm{E}\left[D_{1} D_{n}\right] & \cdots & \mathrm{E}\left[D_{n}^{2}\right] & \mathrm{E}\left[D_{n}^{2}\right] \\ \exp (r T) & \exp (r T) P_{0} & \mathrm{E}{ }^{Q}\left[D_{1}\right] & \cdots & \mathrm{E}{ }^{Q}\left[D_{n}\right] & 0 \\ \vdots \\ c_{1} \\ c_{2} \\ \vdots \\ c_{n} \\ \lambda\end{array}\right]=\left[\begin{array}{c}\mathrm{E}\left[W_{T}^{*}\right] \\ \mathrm{E}\left[W_{T}^{*} P_{T}\right] \\ \mathrm{E}\left[W_{T}^{*} D_{1}\right] \\ \mathrm{E}\left[W_{T}^{*} D_{2}\right] \\ \vdots \\ \mathrm{E}\left[W_{T}^{*} D_{n}\right] \\ \exp (r t) W_{0}\end{array}\right]$

or, in matrix notation:

$$
\Sigma \eta=\epsilon
$$

where $\lambda$ is the Lagrange multiplier corresponding to the budget equation.

Inverting (3.13) to compute

$$
\hat{\eta}=\Sigma^{-1} \epsilon
$$

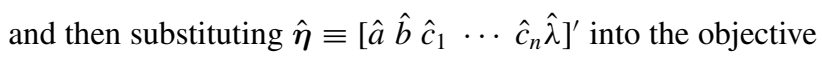
function (3.9) yields the optimal value for a given subproblem. Repeating this procedure for all $\left(\begin{array}{l}N \\ n\end{array}\right)$ subproblems and selecting the best of these solutions gives an approximate solution to (3.9)-(3.11).

However, for some utility functions, it is necessary to impose the solvency constraints (3.8), in which case the solution to the subproblem cannot be simplified according to (3.14).

\subsection{Minimizing weighted mean-squared error}

A third alternative to the two approaches outlined in sections 3.1 and 3.2 is to maximize expected utility but where we substitute an approximation for the utility function. This yields a weighted mean-squared-error objective function where the weighting function is the second derivative of the utility function evaluated at the optimal end-of-period wealth $W_{T}^{*}$. This is a hybrid of the two approaches proposed above that provides important economic motivation for mean-squared error, and approximates the direct approach of maximizing expected utility described in section 3.1.

Specifically, consider the subproblem of section 3.1 in which we maximize expected utility holding fixed the strike prices $\left\{k_{i}\right\}$ :

$$
\operatorname{Max}_{\left\{a, b, c_{i}\right\}} \mathrm{E}\left[U\left(V_{T}\right)\right]
$$

subject to the budget (3.7) and solvency constraints (3.8). Take a Taylor expansion of $U\left(W_{T}^{*} \pm \lambda\left(W_{T}^{*}-V_{T}\right)\right)$ about the global optimal $W_{T}^{*}$ :

$$
\begin{aligned}
& \mathrm{E}\left[U\left(W_{T}^{*} \pm \lambda\left(W_{T}^{*}-V_{T}\right)\right)\right] \\
& \approx \mathrm{E}\left[U\left(W_{T}^{*}\right)\right] \pm \lambda \mathrm{E}\left[\left(W_{T}^{*}-V_{T}\right) U^{\prime}\left(W_{T}^{*}\right)\right] \\
& \quad+\frac{\lambda^{2}}{2} \mathrm{E}\left[\left(W_{T}^{*}-V_{T}\right)^{2} U^{\prime \prime}\left(W_{T}^{*}\right)\right] .
\end{aligned}
$$

If $V_{T}$ were 'budget feasible', by which we mean that $\exp (-r T) \mathrm{E}^{Q}\left[V_{T}\right]=W_{0}$, and $V_{T}$ were sufficiently close to $W_{T}^{*}$, then this implies that $\pm \lambda\left(W_{T}^{*}-V_{T}\right)$ is a feasible direction of travel from $W_{T}^{*}$. For sufficiently small $\lambda$, (3.15) implies that

$$
\mathrm{E}\left[\left(W_{T}^{*}-V_{T}\right) U^{\prime \prime}\left(W_{T}^{*}\right)\right]=0
$$

under certain regularity conditions. Therefore, maximizing $\mathrm{E}\left[U\left(V_{T}\right)\right]$ should be equivalent to maximizing

$$
\frac{1}{2} \mathrm{E}\left[\left(W_{T}^{*}-V_{T}\right)^{2} U^{\prime \prime}\left(W_{T}^{*}\right)\right]
$$

for $V_{T}$ sufficiently close to $W_{T}^{*}$. This gives rise to a third approach to the buy-and-hold asset-allocation problem, one that involves approximating $W_{T}^{*}$ in mean-square rather than explicitly maximizing expected utility:

$$
\operatorname{Min}_{\left\{a, b, c_{i}, k_{i}\right\}} \mathrm{E}\left[-U^{\prime \prime}\left(W_{T}^{*}\right)\left(W_{T}^{*}-V_{T}\right)^{2}\right]
$$

subject to

$$
\begin{aligned}
& V_{T} \equiv a \exp (r T)+b P_{T}+c_{1} D_{1}+c_{2} D_{2}+\cdots+c_{n} D_{n} \\
& W_{0}=\exp (-r T) \mathrm{E}^{Q}\left[V_{T}\right] .
\end{aligned}
$$

For CRRA utility, we still need to impose solvency constraints, but even with such constraints we can solve the subproblem much more quickly in the weighted mean-squared error case than in the maximization of expected utility proposed in section 3.1. Indeed, the computational challenges for the weighted mean-squared error approach are comparable to the mean-squared error approach of section 3.2.

A potential difficulty with the utility-weighted meansquared-error approach is that some of the expectations in (3.17) may not be defined. Even when the expectations are defined, it is possible that some of them are very difficult to compute when they are ill-conditioned, i.e. 'close' to being undefined. In such cases the approach either will not work or will be very difficult to implement. This typically occurs for low values of relative risk aversion. Fortunately, it is precisely for low values of risk aversion that a direct maximization of expected utility works best. The reason is that the discretization of the support of $P_{T}$ leads to approximation errors that can be extreme for high values of risk aversion. In particular, the discretized distribution has finite support, hence the optimal buy-and-hold strategy obtained with this distribution may perform poorly outside this finite support. The power-law specification of CRRA preferences will magnify small approximation errors of this type when the risk-aversion parameter is large.

Therefore, the maximization of expected utility and the minimization of utility-weighted mean-squared-error complement each other. As we will see in section 5, when both approaches work well, they result in almost identical portfolios and certainty equivalents. Therefore, in the 
numerical examples of section 5, we will maximize expected utility for low values of relative risk aversion and minimize utility-weighted mean-squared-error for higher values when computing the utility-optimal buy-and-hold portfolios.

\section{Three leading cases}

To derive the optimal buy-and-hold portfolios according to the three criteria of section 3 , we require a few auxiliary results that depend on the specific utility function of the investor and the stochastic process for stock prices. In this section, we derive these results for CRRA and CARA utility under three leading cases for the stock-price process: geometric Brownian motion (section 4.1), the trending Ornstein-Uhlenbeck process (section 4.2), and a bivariate linear diffusion process with a stochastic mean-reverting drift (section 4.3).

In the case of geometric Brownian motion, the required results are straightforward-we are able to characterize $W_{T}^{*}$ explicitly for both CRRA and CARA preferences, and all three approaches to the optimal buy-and-hold portfolio can be readily implemented. However, for the other two stochastic processes, the optimal dynamic asset-allocation strategies are path dependent, which implies that no buy-and-hold portfolio of stocks, bonds and European call options can ever achieve the same certainty equivalents as the optimal dynamic strategies. In such situations, we propose an alternative to $W_{T}^{*}$ as a target for the optimal buy-and-hold portfolio, and derive this alternative explicitly in sections 4.2 and 4.3.

\subsection{Geometric Brownian motion}

In the case of geometric Brownian motion, the stock price $P_{t}$ satisfies the following stochastic differential equation (SDE):

$$
\mathrm{d} P_{t}=\mu P_{t} \mathrm{~d} t+\sigma P_{t} \mathrm{~d} B_{t}
$$

where $B_{t}$ is a standard Brownian motion. Recall that the standard asset-allocation problem in the absence of derivatives is given by (3.2) and (3.3):

$$
\operatorname{Max}_{\left\{\omega_{t}\right\}} \mathrm{E}\left[U\left(W_{T}\right)\right]
$$

subject to the budget equation

$$
\mathrm{d} W_{t}=\left[r+\omega_{t}(\mu-r)\right] W_{t} \mathrm{~d} t+\omega_{t} W_{t} \sigma \mathrm{d} B_{t}
$$

where $\omega_{t}$ is the fraction of the investor's portfolio invested in the stock at time $t$ (see Merton $(1969,1971)$ for a more detailed exposition). For concreteness, we consider two specific utility functions: constant absolute risk-aversion (CARA) and constant relative risk-aversion (CRRA) utility. These are well-known utility functions for which there are closedform solutions to the standard asset-allocation problem. In particular, for CRRA utility, we have:

$U\left(W_{T}\right)=\frac{W_{T}^{\gamma}}{\gamma}$

$W_{T}^{*}=W_{0} \exp \left(r T-\frac{\xi^{2} T(2 \gamma-1)}{2(1-\gamma)^{2}}+\frac{\xi B_{T}}{(1-\gamma)}\right)$

$\omega_{t}^{*}=\frac{\mu-r}{(1-\gamma) \sigma^{2}}$ and for CARA utility,

$U\left(W_{T}\right)=-\frac{\exp \left(-\gamma W_{T}\right)}{\gamma}$

$W_{T}^{*}=\frac{\gamma W_{0} \exp (r T)+\xi^{2} T+\xi B_{T}}{\gamma}, \quad \xi \equiv \frac{\mu-r}{\sigma}$

$\omega_{t}^{*}=\frac{\exp (-r(T-t)) \xi}{\gamma \sigma W_{t}}$.

Given these closed-form solutions, we can make explicit comparisons of the optimal buy-and-hold portfolio of stocks, bonds and options with the standard optimal asset-allocation strategies for the two utility functions.

\subsection{The Ornstein-Uhlenbeck process}

If stock prices are predictable to some degree, the assetallocation problem becomes considerably more challenging since the optimal investment strategy is path-dependent. This implies that of $W_{T}^{*}$ is also path-dependent and very difficult to compute explicitly, hence the mean-squared-error approaches of sections 3.2 and 3.3 are not feasible. However, in certain cases, it is possible to derive an upper bound on the certainty equivalent of the optimal buy-and-hold portfolio of stocks, bonds and options, which provides some indication of the benefits of options in replicating dynamic investment strategies. We present such an upper bound in this section for the case where log-prices $X_{t} \equiv \log P_{t}$ follow a trending Ornstein-Uhlenbeck process ${ }^{14}$ :

$$
\mathrm{d} X_{t}=\left[-\delta\left(X_{t}-\mu t-X_{0}\right)+\mu\right] \mathrm{d} t+\sigma \mathrm{d} B_{t}, \quad \delta>0 .
$$

which has the solution:

$$
X_{t}=X_{0}+\mu t+\sigma \exp (-\delta t) \int_{0}^{t} \exp (\delta s) \mathrm{d} B_{s} .
$$

The solution to the standard asset-allocation problem (3.2) and (3.3) in this case is characterized by the following HamiltonJacobi-Bellman equation:

$$
\begin{aligned}
0= & \operatorname{Max}_{\omega_{t}}\left\{J_{t}+W_{t} J_{W}\left(r+\omega_{t}\left[-\delta\left(X_{t}-\mu t-X_{0}\right)+\mu\right.\right.\right. \\
& \left.\left.+\frac{1}{2} \sigma^{2}-r\right]\right)+J_{X}\left(-\delta\left(X_{t}-\mu t-X_{0}\right)+\mu\right) \\
& \left.+\frac{1}{2} \omega_{t}^{2} \sigma^{2} W_{t}^{2} J_{W W}+\frac{1}{2} \sigma^{2} J_{X X}+\sigma^{2} \omega_{t} W_{t} J_{X W}\right\}
\end{aligned}
$$

where

$$
J\left(W_{t}, X_{t}, t\right) \equiv \operatorname{Max}_{\omega_{t}} \mathrm{E}_{t}\left[U\left(W_{T}\right)\right] .
$$

The solutions to (4.10) for CRRA and CARA utility are given in the appendix.

Because $W_{T}^{*}$ is path-dependent in this case, even if we allow the number of options $n$ in the buy-and-hold portfolio to increase without bound, the certainty equivalent of the buyand-hold portfolio will never approach the certainty equivalent of $W_{T}^{*}$. However, an upper bound on the certainty equivalent of any buy-and-hold portfolio can be derived by allowing the investor to purchase an unlimited number of options at all

${ }^{14}$ See Lo and Wang (1995) for a more detailed exposition of its properties. We also derive results for the standard Ornstein-Uhlenbeck process (without trend), which are included in the appendix. 
possible strike prices. The certainty equivalent of the end-ofperiod wealth in this case, which we denote by $V_{T}^{\infty}$, is clearly an upper bound for any buy-and-hold portfolio containing a finite number $n$ of options.

To derive $V_{T}^{\infty}$, we require the conditional state-price density of the terminal stock price $P_{T}$, defined as:

$$
\pi_{T}^{b} \equiv \mathrm{E}\left[\pi_{T} \mid P_{T}=b\right]
$$

where $\pi_{T}$ is the unconditional state-price density of the terminal stock price ${ }^{15}$. The economic interpretation of $\pi_{T}^{b}$ is the price per unit probability of 1 unit of wealth at time $T$ in the event that $P_{T}=b$. By definition, $\pi_{T}^{b}$ is given by:

$$
\pi_{T}^{b}=\mathrm{E}\left[\pi_{T} \mid P_{T}=b\right]=\frac{\mathrm{E}\left[\pi_{T} 1_{\left\{P_{T}=b\right\}}\right]}{\mathrm{E}\left[1_{\left\{P_{T}=b\right\}}\right]} .
$$

The numerator of (4.13) is computed by applying Girsanov's theorem and noting that the Radon-Nikodym derivative $\mathrm{d} Q / \mathrm{d} F$ of the equivalent martingale measure $Q$ with respect to the true probability measure $F$ is equal to $\exp (r T) \pi_{T}$. Under $Q$, the stock price at time $T$ is given by

$$
P_{T}^{Q}=\exp \left(Z_{T}\right) \equiv P_{0} \exp \left(\left(r-\frac{\sigma^{2}}{2}\right) T+\sigma \widehat{B_{T}}\right)
$$

where $\widehat{B_{T}}$ is a standard Brownian motion under $Q$. Under the true probability measure, $F$, recall that the stock price at time $T$ is given by

$$
P_{T}=\exp \left(X_{T}\right) \equiv \exp \left(X_{0}+\mu T+\sigma \mathrm{e}^{-\delta T} \int_{0}^{T} \mathrm{e}^{\delta s} \mathrm{~d} B_{s}\right) .
$$

With this in mind, we can write (4.13) as

$$
\pi_{T}^{b}=\frac{\exp (-r T) f_{P_{T}}^{Q}(b)}{f_{P_{T}}(b)}
$$

where $f_{P_{T}}$ and $f_{P_{T}}^{Q}$ denote the log-normal density functions of $P_{T}$ under $F$ and $Q$ respectively. Simplifying (4.16) yields:

$$
\begin{aligned}
\pi_{T}^{b} & =\left(\frac{\sigma_{x}}{\sigma_{z}}\right) \exp (-r T \\
& \left.-\frac{1}{2}\left[\left(\frac{\log b-\mu_{z}}{\sigma_{z}}\right)^{2}-\left(\frac{\log b-\mu_{x}}{\sigma_{x}}\right)^{2}\right]\right)
\end{aligned}
$$

where

$$
\begin{array}{ll}
\mu_{x}=X_{0}+\mu T, & \sigma_{x}^{2}=\frac{\sigma^{2}}{2 \delta}(1-\exp (-2 \delta T)) \\
\mu_{z}=X_{0}+\left(r-\frac{\sigma^{2}}{2}\right) T, & \sigma_{z}^{2}=\sigma^{2} T .
\end{array}
$$

Using $\pi_{T}^{b}$ as the state-price density process, we can derive the optimal buy-and-hold portfolio in which options of all possible strikes may be included. Using the approach proposed in Cox

15 See Duffie (1996) for a more detailed exposition of state-price densities. and Huang (1989) for the case of CRRA utility, the problem reduces to:

$$
\max \mathrm{E}\left[\frac{\left(V_{T}\right)^{\gamma}}{\gamma}\right] \quad \text { subject to } \quad \mathrm{E}\left[\pi_{T}^{b} V_{T}\right]=W_{0}
$$

which has the solution:

$$
V_{T}^{\infty}=\frac{W_{0}\left(\pi_{T}^{b}\right)^{\frac{1}{\gamma-1}}}{\mathrm{E}\left[\left(\pi_{T}^{b}\right)^{\frac{\gamma}{\gamma-1}}\right]}
$$

where

$$
\begin{aligned}
& \mathrm{E}\left[\left(\pi_{T}^{b}\right)^{\frac{\gamma}{\gamma-1}}\right] \\
& =\frac{\sigma_{o}}{\sigma_{x}}\left(\frac{\sigma_{x}}{\sigma_{z}}\right)^{\frac{\gamma}{\gamma-1}} \exp \left(\frac{-r T \gamma}{\gamma-1}+\frac{\gamma\left[\mu_{x}-\mu_{z}\right]^{2}}{2[\gamma-1]\left[\gamma \sigma_{x}^{2}-\sigma_{z}^{2}\right]}\right)
\end{aligned}
$$

and

$$
\sigma_{o}^{2}=\frac{\sigma_{x}^{2} \sigma_{z}^{2}(\gamma-1)}{\left(\gamma \sigma_{x}^{2}-\sigma_{z}^{2}\right)} .
$$

This, in turn, implies:

$$
\begin{aligned}
U^{\infty} \equiv \mathrm{E}\left[\frac{\left(V_{T}^{\infty}\right)^{\gamma}}{\gamma}\right] & =\frac{W_{0}^{\gamma}}{\gamma} \mathrm{E}\left[\left(\pi_{T}^{b}\right)^{\frac{\gamma}{\gamma-1}}\right]^{1-\gamma} \\
\mathrm{CE}\left(V_{T}^{\infty}\right) & =\left(\gamma U^{\infty}\right)^{\frac{1}{\gamma}}
\end{aligned}
$$

where $\mathrm{CE}(\cdot)$ denotes the certainty equivalent operator.

The case of CARA utility can also be handled in a similar manner.

Having solved for the optimal buy-and-hold portfolio and its certainty equivalent in the infinite options case, we can now compare this upper bound to the optimal buy-andhold portfolios with a finite number of options. We use the same method as in the geometric Brownian motion case (see section 4.1), hence we omit the details.

\subsection{A bivariate linear diffusion process}

We now turn to a third set of price dynamics for $P_{t}$, one in which there are two sources of uncertainty, implying that markets are incomplete. Nevertheless, we are still able to compute optimal buy-and-hold portfolios of stocks, bonds and options, and can also derive the upper bound to the buy-andhold certainty equivalents as in section 4.2. Specifically, let $X_{t} \equiv \log P_{t}$ satisfy the following bivariate linear diffusion process:

$$
\begin{aligned}
\mathrm{d} X_{t} & =\left(\mu_{t}-\frac{\sigma_{1}^{2}}{2}\right) \mathrm{d} t+\sigma_{1} \mathrm{~d} B_{1 t} \\
\mathrm{~d} \mu_{t} & =\kappa\left(\theta-\mu_{t}\right) \mathrm{d} t+\sigma_{2} \mathrm{~d} B_{2 t}
\end{aligned}
$$

where $B_{1 t}$ and $B_{2 t}$ are two standard Brownian motions with instantaneous correlation coefficient $\rho$. Kim and Omberg $(1993,1996)$ derive the optimal value function for the standard asset-allocation problem with these price dynamics for an investor with CARA utility. Despite the fact that markets are incomplete, it is clear that options can be replicated using 
trading strategies in only the stock and the bond ${ }^{16}$, hence options can be priced by arbitrage in this case. Therefore, we can perform the same analysis for these dynamics as we did for geometric Brownian motion in section 4.1 and the OrnsteinUhlenbeck process in section 4.2.

To derive $V_{T}^{\infty}$ for the bivariate diffusion (4.22) and (4.23), we perform a similar set of calculations as in section 4.2. We begin by solving (4.22) and observing that $P_{T}$ is log-normally distributed with parameters:

$$
\begin{aligned}
\mu_{X}= & X_{0}+\left(\theta-\frac{\sigma_{1}^{2}}{2}\right) T+\frac{\theta-\mu_{o}}{\kappa}(\exp (-\kappa T)-1) \\
\sigma_{x}^{2}= & \sigma_{1}^{2} T+\frac{2 \sigma_{1} \sigma_{2} \rho}{\kappa}\left[T+\frac{\exp (-\kappa T)}{\kappa}-\frac{1}{\kappa}\right] \\
& +\frac{\sigma_{2}^{2}}{\kappa^{3}}\left[T \kappa-\frac{3}{2}+2 \exp (-\kappa T)-\frac{\exp (-2 \kappa T)}{2}\right] .
\end{aligned}
$$

The conditional state-price density then follows in the same manner as (4.17):

$$
\begin{aligned}
\pi_{T}^{b}= & \left(\frac{\sigma_{x}}{\sigma_{z}}\right) \exp (-r T \\
& \left.-\frac{1}{2}\left[\left(\frac{\log b-\mu_{z}}{\sigma_{z}}\right)^{2}-\left(\frac{\log b-\mu_{x}}{\sigma_{x}}\right)^{2}\right]\right)
\end{aligned}
$$

where

$$
\mu_{z}=X_{0}+\left(r-\frac{\sigma^{2}}{2}\right) T, \quad \sigma_{z}^{2}=\sigma^{2} T
$$

With the conditional state-price density in hand, $V_{T}^{\infty}$ and its certainty equivalent are readily derived.

\section{Numerical results}

To illustrate the practical relevance of our optimal buy-andhold portfolio, we provide numerical results in this section for CRRA preferences under each of the three stochastic processes of section 4 using the nonlinear programming solver LOQO and the algebraic mathematical programming language AMPL $^{17}$. Before turning to those results, we begin with a simple example to motivate our analysis. Let stock prices follow geometric Brownian motion (4.1) and set

$$
\begin{array}{ll}
U\left(W_{T}\right)=\frac{W_{T}^{\gamma}}{\gamma}, & \gamma=-4, \\
W_{0}=\$ 100000, & T=20 \text { years, } \\
P_{0}=\$ 50, & r=0.05, \\
\mu=0.15, & \sigma=0.20
\end{array}
$$

which implies a relative risk-aversion coefficient of 5, a portfolio weight $\omega_{t}^{*}$ of $50 \%$ for the stock in the optimal dynamic asset-allocation policy (4.4), and a certainty equivalent of $\$ 448169$ for $W_{T}^{*}$. Now consider the problem of constructing an optimal buy-and-hold portfolio containing stocks, bonds, and

${ }^{16}$ For further discussion, see Lo and Wang (1995).

${ }^{17}$ AMPL is described in Fourer et al (1999). Information on LOQO can be obtained from http://www.princeton.edu/ loqo/. a maximum of two options, assuming that there are only four possible options to choose from, with the following strikes:

$$
k_{1}=\$ 176, \quad k_{2}=\$ 976, \quad k_{3}=\$ 1775, \quad k_{4}=\$ 2575 .
$$

For the approach outlined in section 3.1, we maximize the expected utility:

$$
\operatorname{Max}_{\left\{a, b, c_{i}, k_{i}\right\}} \mathrm{E}\left[U\left(V_{T}\right)\right]
$$

subject to

$V_{T} \equiv a \exp (r T)+b P_{T}+c_{1} D_{1}+c_{2} D_{2}$

$W_{0}=\exp (-r T) \mathrm{E}^{Q}\left[V_{T}\right]$

and the corresponding solvency constraints. We discretize the support of $P_{T}$ using a grid of 4000 points, chosen in such a way that the weight associated with each point in the objective function is equal to $1 / 4000$. A direct optimization then yields the following certainty equivalents for subproblems of the optimal buy-and-hold problem for the various combinations of strikes:

$\begin{array}{cc}\text { Options Used: } & \mathrm{CE}\left(V_{T}^{*}\right) \text { : } \\ 1 \text { and 2 } & \$ 447307 \\ 1 \text { and 3 } & \$ 447137 \\ 1 \text { and 4 } & \$ 447067 \\ 2 \text { and 3 } & \$ 437971 \\ 2 \text { and 4 } & \$ 437850 \\ 3 \text { and 4 } & \$ 436506\end{array}$

From (5.1), it is apparent that the optimal buy-and-hold strategy is to use options with strikes $k_{1}=176$ and $k_{2}=976$, and the optimal portfolio positions are:

$$
a^{*}=\$ 36097, \quad b^{*}=1521, \quad c_{1}^{*}=-907, \quad c_{2}^{*}=-353 .
$$

With only two options, the optimal buy-and-hold portfolio yields an estimated certainty equivalent of $\$ 447307^{18}$, which is $99.8 \%$ of the certainty equivalent of the optimal dynamic asset-allocation strategy, a strategy that requires continuous trading over a 20 -year period!

Note that the portfolio weights implied by the positions (5.2) are $36.1 \%$ in bonds, $76.1 \%$ in stocks and $-12.2 \%$ in options. The optimal buy-and-hold portfolio consists of shorting options 1 and 2, and investing the proceedsapproximately $\$ 12100$ - in stocks and bonds along with the initial wealth of $\$ 100000$.

Alternatively, we can minimize the mean-squared error between $V_{T}$ and $W_{T}^{*}$ according to section 3.2:

$$
\operatorname{Min}_{\left\{a, b, c_{i}, k_{i}\right\}} \mathrm{E}\left[\left(W_{T}^{*}-V_{T}\right)^{2}\right]
$$

subject to

$$
V_{T} \equiv a \exp (r T)+b P_{T}+c_{1} D_{1}+c_{2} D_{2}
$$$$
W_{0}=\exp (-r T) \mathrm{E}^{Q}\left[V_{T}\right]
$$

${ }^{18}$ The estimation error is due to the discretization of the distribution of $P_{T}$. Once we obtain the strategy (5.2), we can compute the certainty equivalent exactly, and in this case, it is $\$ 446034$, which is $99.5 \%$ of the certainty equivalent of the optimal dynamic asset-allocation strategy. 
and also subject to the solvency constraints (3.8). The rootmean-squared-error (RMSE) (as a percentage of $\mathrm{E}\left[W_{T}^{*}\right]$ ) of each of the subproblems is given by:

$\begin{array}{cc}\text { Options Used: } & \text { RMSE (\%): } \\ 1 \text { and } 2 & 6.27 \\ 1 \text { and } 3 & 4.73 \\ 1 \text { and } 4 & 5.69 \\ 2 \text { and } 3 & 6.47 \\ 2 \text { and } 4 & 5.75 \\ 3 \text { and } 4 & 9.95\end{array}$

Under the mean-squared-error criterion, the optimal buy-andhold portfolio consists of a different set of options than under the expected-utility criterion-in this case, options 1 and 3 and the optimal positions are:

$a^{*}=\$ 20928, \quad b^{*}=1980, \quad c_{1}^{*}=-1508, \quad c_{2}^{*}=-291$.

With such a buy-and-hold portfolio, the root-mean-squarederror is $4.73 \%$ of the expected value of $W_{T}^{*}$, and the certainty equivalent of this portfolio is $\$ 436034$, which is $97.3 \%$ of the certainty equivalent of the optimal dynamic asset-allocation strategy. Despite the fact that (5.3) is only an indirect method of approximating $W_{T}^{*}$, the certainty equivalent is almost identical to that of the optimal dynamic strategy. The portfolio weights corresponding to (5.3) are $20.9 \%$ in bonds, $99.0 \%$ in stocks and $-19.9 \%$ in options.

Finally, if we minimize the weighted mean-squared-error according to section 3.3 ,

$$
\operatorname{Min}_{\left\{a, b, c_{i}, k_{i}\right\}} \mathrm{E}\left[-U^{\prime \prime}\left(W_{T}^{*}\right)\left(W_{T}^{*}-V_{T}\right)^{2}\right]
$$

subject to

$V_{T} \equiv a \exp (r T)+b P_{T}+c_{1} D_{1}+c_{2} D_{2}$

$W_{0}=\exp (-r T) \mathrm{E}^{Q}\left[V_{T}\right]$

and the solvency constraints (3.8), we obtain the following weighted RMSEs for the various subproblems:

$\begin{array}{cc}\text { Options Used: } & \text { Weighted RMSE: } \\ 1 \text { and } 2 & 0.738 \\ 1 \text { and } 3 & 0.764 \\ 1 \text { and } 4 & 0.777 \\ 2 \text { and } 3 & 1.830 \\ 2 \text { and } 4 & 1.839 \\ 3 \text { and } 4 & 2.013\end{array}$

which yields an optimal buy-and-hold portfolio containing options 1 and 2 and positions:

$$
a^{*}=\$ 35321, \quad b^{*}=1523, \quad c_{1}^{*}=-930, \quad c_{2}^{*}=-349 .
$$

Although the weighted RMSE of the optimal buy-and-hold portfolio, 0.738 , is somewhat difficult to interpret, the certainty of equivalent of the portfolio is $\$ 445967$ which is $99.5 \%$ of the certainty equivalent of the optimal dynamic assetallocation strategy. With portfolio weights of $35.3 \%$ in bonds, $76.2 \%$ in stocks and $-11.5 \%$ in options, the minimum utilityweighted mean-squared-error approach yields an almostidentical solution to the maximum expected-utility approach (recall that the portfolio weights of the latter are $36.1 \%$ in bonds, $76.1 \%$ in stocks and $-12.2 \%$ in options). Therefore, the hybrid approach provides an excellent approximation to the maximization of expected utility.

In sections 5.1-5.3, we perform more computationally intense optimizations for the three stochastic processes of section 4 under CRRA preferences using the three approaches described in section 3: maximizing expected utility, and minimizing mean-squared error and weighted mean-squared error. In particular, for each stochastic process, we compute two optimal buy-and-hold portfolios for each of six different values of the relative risk aversion coefficient (RRA = 1, 2, 5, 10, 15, 20): a utility-optimal buy-and-hold portfolio obtained by either direct maximization of expected utility or minimization of utility-weighted mean-squared error (as in sections 3.1 and 3.3, respectively), and a mean-square-optimal buy-and-hold portfolio (as in section 3.2). For each stochastic process and each value of the relative risk-aversion coefficient, we consider $N=45$ possible strike prices and up to $n=3$ options for the utility-optimal buy-and-hold portfolios and up to $n=5$ options for the mean-square-optimal buy-and-hold portfolios. This yields up to $\left(\begin{array}{c}45 \\ 3\end{array}\right)=14190$ and $\left(\begin{array}{c}45 \\ 5\end{array}\right)=1221759$ subproblems for each of the two optimizations, respectively.

The strikes are selected in the following way. Letting $\mu_{x}$ and $\sigma_{x}$ denote the mean and variance of $X_{T} \equiv \log P_{T}$, we partition the interval $\left[\exp \left(\mu_{x}-3 \sigma_{x}\right), \exp \left(\mu_{x}+3 \sigma_{x}\right)\right]$ into 45 evenly spaced points which we denote by $s_{1} \equiv \exp \left(\mu_{x}-\right.$ $\left.3 \sigma_{x}\right), \ldots, s_{45} \equiv \exp \left(\mu_{x}+3 \sigma_{x}\right)$. We then use these points as our strikes, $k_{i}=s_{i}, i=1, \ldots, 45$. Such a procedure for choosing the set of strikes $\left\{k_{i}\right\}$ is simple to implement, however, more sophisticated methods can be employed to improve the performance of the overall optimization process.

To facilitate comparisons across different optimal buyand-hold portfolios we use one set of 45 strikes for each of the three stochastic processes considered in sections 5.15.3 , i.e. for each stochastic process, we construct one set of 45 strikes and keep these fixed as we vary the values of relative risk aversion and the number of options $n$ in the buyand-hold portfolio. This is clearly suboptimal-for example, when $n=1$, we can optimize the buy-and-hold portfolio over several thousand possible strike prices very quicklybut holding the strikes fixed allows us to gauge the impact of other parameters such as the risk-aversion coefficient and the number of options on the objective function being optimized. In practical applications, the set of possible strikes should be optimized for each specification of the buy-and-hold problem; in our limited experience, simple heuristics for optimizing the set of strikes can lead to substantial improvements in overall performance.

For each of the three cases considered in sections 5.1-5.3, 
we maintain the following set of assumptions:

$$
\begin{aligned}
& U\left(W_{T}\right)=\frac{W_{T}^{\gamma}}{\gamma} \\
& \gamma=0,-1,-4,-9,-14,-19 \\
& W_{0}=\$ 100000 \\
& T=20 \text { years } \\
& P_{0}=\$ 50 \\
& r=0.05 \\
& \mathrm{E}\left[\log \left(P_{t} / P_{t-1}\right)\right]=0.15 \\
& \operatorname{Var}\left[\log \left(P_{t} / P_{t-1}\right)\right]=0.20^{2}
\end{aligned}
$$

where the values of $\gamma$ correspond to relative risk-aversion coefficients of $1,2,5,10,15$, and 20 , respectively.

\subsection{Geometric Brownian motion}

For geometric Brownian motion (4.1), we set the parameters $(\mu, \sigma)$ to match the mean and variance of continuously compounded returns specified in (5.5). Based on our algorithm for constructing the set of strike prices from the distribution of $\log P_{T}$, we select the strikes for our $n$ options from among the following 45 possibilities (in dollars):

$\begin{array}{rrrrr}69 & 401 & 733 & 1066 & 1398 \\ 1731 & 2063 & 2396 & 2728 & 3061 \\ 3393 & 3725 & 4058 & 4390 & 4723 \\ 5055 & 5388 & 5720 & 6052 & 6385 \\ 6717 & 7050 & 7382 & 7715 & 8047 \\ 8379 & 8712 & 9044 & 9377 & 9709 \\ 10042 & 10374 & 10706 & 11039 & 11371 \\ 11704 & 12036 & 12369 & 12701 & 13033 \\ 13366 & 13698 & 14031 & 14363 & 14696\end{array}$

Utility-optimal buy-and-hold portfolios. Table 1 reports the utility-optimal buy-and-hold portfolios for various levels of risk aversion and, for each risk-aversion parameter, for the number of options $n$ varying from 0 to 3 . For example, the first panel of table 1 contains results for the log-utility case $(\gamma=0$, or RRA =1). This is a very low level of risk aversion-by most empirical and experimental accounts, an unrealistically low level — and implies that the investor's objective is to maximize the expected geometric average rate of return of his portfolio. Examples of investors with such preferences are proprietary traders and hedge-fund managers. The results for the RRA $=1$ panel were obtained by maximizing expected utility directly using a discretized distribution for $P_{T}$ (see section 3.1). The results for the remaining five panels of table 1 were obtained by minimizing the utility-weighted mean-squared error (see section 3.3).

The first row of table 1's first panel corresponds to the optimal buy-and-hold portfolio with no options $(n=0)$ for log-utility, the optimal portfolio is to put $100 \%$ of the investor's wealth into the stock ${ }^{19}$. Not surprisingly, the certainty equivalent of such a strategy is only $20.2 \%$ of the certainty equivalent of the optimal dynamic strategy $\mathrm{CE}\left(W_{T}^{*}\right)$.

${ }^{19}$ In fact, in the absence of solvency constraints, the optimal portfolio weight for the stock would be much greater than $100 \%$, i.e. for CRRA preferences, the solvency constraints are binding.

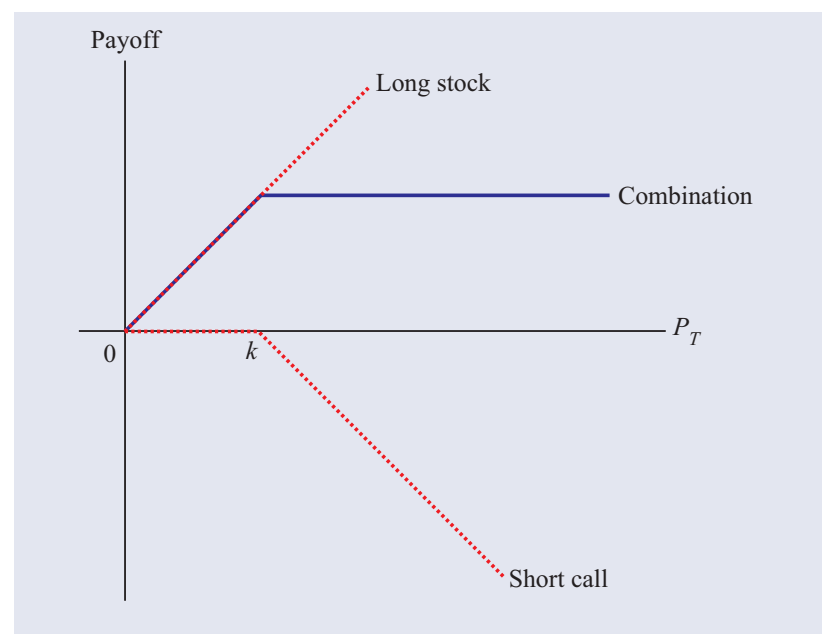

Figure 1. Payoff diagram of hedged position (long stock and short call)

By not allowing the investor to trade at all over the 20year period, and without access to any options, the investor's welfare is reduced by approximately $80 \%$. As the number of options is increased, his welfare increases so that for $n=3$ options the certainty equivalent of the optimal buy-and-hold is $92.2 \%$ of $\mathrm{CE}\left(W_{T}^{*}\right)$.

For log utility, it is interesting to note that the RMSE is approximately $3650 \%$ even for $n=3$ and despite the fact that the certainty equivalent of the optimal buy-and-hold portfolio is close to that of the optimal dynamic investment policy. This, and the very slow rate at which the RMSE decreases as we increase $n$ from 0 to 3 , suggests that it may be possible to obtain an excellent approximation to the optimal dynamic strategy - in terms of expected utility - without being able to approximate $W_{T}^{*}$ very well in mean-square.

Note that within each relative risk-aversion panel of table 1 , the RMSEs decrease monotonically as the number of options $n$ increases from 0 to 3 . This, of course, need not be the case since we are maximizing expected utility, not minimizing RMSE. In fact, it is quite possible for the RMSE to increase as we increase $n$. However, the fact that they do decrease monotonically suggests that there is some correlation between smaller RMSE and a more preferred buy-and-hold portfolio. Of course, as $n$ becomes arbitrarily large, the RMSE must converge to 0 .

Perhaps the most interesting feature of table 1 is how the results fall naturally into two distinct groups. The first group consists of the first two panels, corresponding to investors who are not very risk averse (relative risk-aversion coefficients of 1 and 2, respectively) and who, in the standard dynamic asset-allocation framework, would optimally hold more than $100 \%$ of their wealth in the risky asset. In a buy-and-hold portfolio without options $(n=0)$, these investors are bound by the solvency constraints (3.8), making it difficult for them to approximate $\mathrm{CE}\left(W_{T}^{*}\right)$ very well (the certainty equivalents $\mathrm{CE}\left(V_{T}^{*}\right)$ of the optimal buy-and-hold portfolios are only $20.2 \%$ of $\mathrm{CE}\left(W_{T}^{*}\right)$ for the log-utility investor and $81.9 \%$ for the investor with RRA $=2$ ). Options are of particular benefit to these investors, who purchase call options so that they can 
Table 1. Utility-optimal buy-and-hold portfolios of stocks, bonds and $n$ European call options for CRRA utility under geometric Brownian motion stock-price dynamics with parameters $(\mu, \sigma)$ calibrated to match the following moments: $\mathrm{E}\left[\log \left(P_{t} / P_{t-1}\right)\right]=0.15$,

$\operatorname{Var}\left[\log \left(P_{t} / P_{t-1}\right)\right]=0.04$. Other calibrated parameters include: riskless rate $r=5 \%$, initial stock price $P_{0}=\$ 50$, initial wealth $W_{0}=\$ 100000$, and time period $T=20$ years. 'RRA' denotes the coefficient of relative risk aversion, ' $\mathrm{CE}\left(W_{T}^{*}\right)$ ' denotes the certainty equivalent of the optimal dynamic stock/bond policy, and ' $\mathrm{CE}\left(V_{T}^{*}\right)$ ' denotes the certainty equivalent of the optimal buy-and-hold portfolio, reported as a percentage of $\mathrm{CE}\left(W_{T}^{*}\right)$.

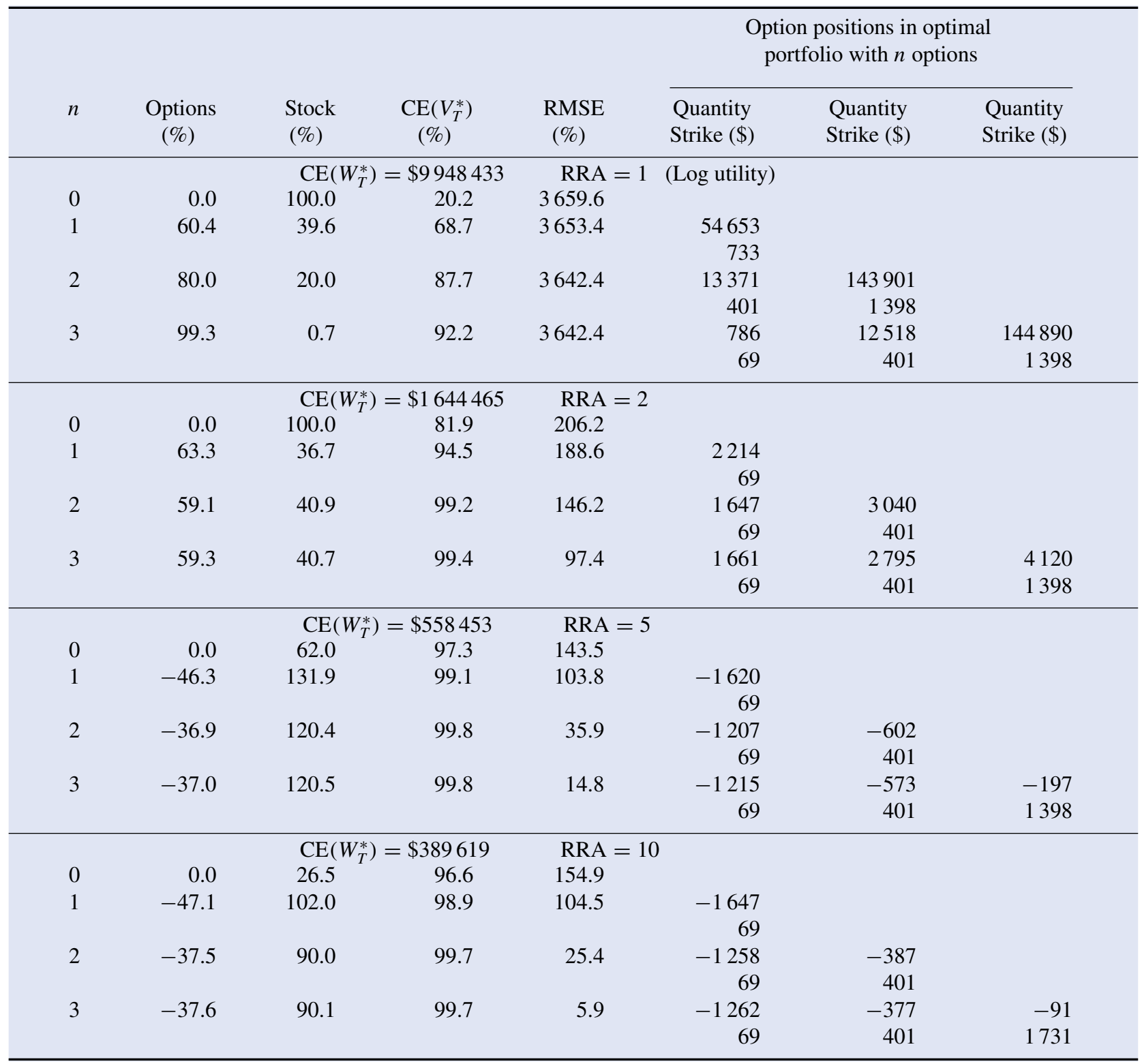

increase their risk exposure ${ }^{20}$. They do not invest in bonds at all, but divide their wealth between stocks and options. As the number of options allowed increases, the fraction of wealth devoted to options in the optimal buy-and-hold portfolio for the log-utility investor also increases, from $60.4 \%$ for $n=1$ to $99.3 \%$ for $n=3$. For a relative risk-aversion coefficient of 2 , the proportion of the optimal buy-and-hold portfolio devoted to options declines slightly as $n$ increases, apparently stabilizing at approximately $59 \%$ for $n=3$.

${ }^{20}$ Call options are generally more risky than the underlying stock on which they are based. See, for example, Cox and Rubinstein (1985).
The second group consists of the remaining four panels, which correspond to investors who, in the standard dynamic asset-allocation framework, would optimally hold less than $100 \%$ of their wealth in the risky asset. For these investors a buy-and-hold portfolio with no options has a certainty equivalent that is approximately $97 \%$ of $\mathrm{CE}\left(W_{T}^{*}\right)$. It is remarkable that a well-chosen buy-and-hold portfolio in the stock and the bond can do so well over a 20-year horizon.

When just 1 or 2 options are added to the buy-and-hold portfolio in these cases, the certainty equivalents $\mathrm{CE}\left(V_{T}^{*}\right)$ of the optimal portfolios increase to approximately $99.7 \%$ of 
Table 1. Continued.

\begin{tabular}{|c|c|c|c|c|c|c|c|}
\hline \multirow[b]{2}{*}{$n$} & \multirow[b]{2}{*}{$\begin{array}{l}\text { Options } \\
(\%)\end{array}$} & \multirow[b]{2}{*}{$\begin{array}{l}\text { Stock } \\
(\%)\end{array}$} & \multirow[b]{2}{*}{$\begin{array}{l}\mathrm{CE}\left(V_{T}^{*}\right) \\
(\%)\end{array}$} & \multirow[b]{2}{*}{$\begin{array}{l}\text { RMSE } \\
(\%)\end{array}$} & \multicolumn{3}{|c|}{$\begin{array}{l}\text { Option positions in optimal } \\
\text { portfolio with } n \text { options }\end{array}$} \\
\hline & & & & & $\begin{array}{l}\text { Quantity } \\
\text { Strike (\$) }\end{array}$ & $\begin{array}{l}\text { Quantity } \\
\text { Strike (\$) }\end{array}$ & $\begin{array}{l}\text { Quantity } \\
\text { Strike (\$) }\end{array}$ \\
\hline & & $\mathrm{CE}(\mathrm{I}$ & $=\$ 345561$ & RRA & & & \\
\hline 0 & 0.0 & 16.2 & 97.2 & 124.0 & & & \\
\hline 1 & -37.1 & 76.6 & 99.1 & 82.3 & $\begin{array}{r}-1297 \\
69\end{array}$ & & \\
\hline 2 & -29.6 & 67.1 & 99.8 & 17.6 & $\begin{array}{r}-1000 \\
69\end{array}$ & $\begin{array}{r}-262 \\
401\end{array}$ & \\
\hline 3 & -29.7 & 67.2 & 99.8 & 4.2 & $\begin{array}{r}-1003 \\
69\end{array}$ & $\begin{array}{r}-256 \\
401\end{array}$ & $\begin{array}{r}-50 \\
1731\end{array}$ \\
\hline & & $\mathrm{CE}(\mathrm{I}$ & $=\$ 325437$ & RRA & & & \\
\hline 0 & 0.0 & 11.6 & 97.7 & 101.0 & & & \\
\hline 1 & -30.0 & 60.7 & 99.3 & 66.5 & $\begin{array}{r}-1048 \\
69\end{array}$ & & \\
\hline 2 & -24.0 & 53.0 & 99.8 & 13.3 & $\begin{array}{r}-812 \\
69\end{array}$ & $\begin{array}{r}-196 \\
401\end{array}$ & \\
\hline 3 & -24.0 & 53.1 & 99.8 & 3.2 & $\begin{array}{r}-814 \\
69\end{array}$ & $\begin{array}{r}-192 \\
401\end{array}$ & $\begin{array}{r}-34 \\
1731\end{array}$ \\
\hline
\end{tabular}

$\mathrm{CE}\left(W_{T}^{*}\right)$. In contrast to the first two panels, investors with higher risk-aversion parameters are net sellers of call options, forgoing some of the upside gain in order to limit losses on the downside. The value of these option positions ranges from $24 \%$ to $37 \%$ of their initial wealth. The optimal buy-and-hold portfolios invest the option premia, together with the initial wealth of $\$ 100000$, in stocks and bonds.

The combination of a short position in a call option and a long position in the underlying stock is often called a 'hedged position' since the gains (losses) of one security offset to some degree the losses (gains) of the other. Figure 1 provides an example of such a hedged position: a long position in one share of stock and a short position in a call option on that stock with strike price $k$. The combination yields a payoff that has limited upside-beyond $k$, the payoff is constant at $k$-which a sufficiently risk-averse investor might find attractive, since he receives cash now in exchange for an uncertain upside.

For risk-aversion coefficients greater than or equal to 5 , table 1 shows that the optimal buy-and-hold portfolios all include hedged positions in which part of the upside potential in the stock is relinquished in exchange for option premia that are invested in stocks and bonds. For a relative risk-aversion coefficient of 10, the optimal buy-and-hold portfolio with 3 options consists of a $-37.6 \%$ investment in options, $90.1 \%$ in the stock, and $47.5 \%$ in bonds. Since this portfolio yields an excellent approximation to the optimal dynamic investment strategy (it has a certainty equivalent $\operatorname{CE}\left(V_{T}^{*}\right)$ of $99.7 \%$ ), we can be fairly confident that these rather unorthodox positions do, in fact, accurately represent the investor's preferences. Indeed, by graphing the payoff diagram of this optimal buyand-hold portfolio along the lines of figure 1, we can obtain a visual representation of the investor's dynamic risk exposures at a single point in time.
A common characteristic in all of the panels of table 1 is the optimal strike prices of the options in the buy-and-hold portfolio. Despite the fact that the possible strikes range from $\$ 69$ to $\$ 14696$, the highest strike selected by the optimization algorithm is $\$ 1731$. Under geometric Brownian motion, the expected stock price 20 years into the future is:

$\mathrm{E}_{0}\left[P_{T}\right]=P_{0} \exp (\mu T)=\$ 50 \times \exp (0.17 \times 20)=\$ 1498$.

Therefore, almost all of the options selected by the optimal buyand-hold portfolio are in-the-money relative to the expected terminal price $\mathrm{E}_{0}\left[P_{T}\right]$, which characterizes another aspect of the investor's risk profile.

Also, the fact that among the 45 possible strikes, only 5 are employed in the optimal buy-and-hold portfolios over the range of relative risk-aversion coefficients from 1 to 20 suggests the possibility of standardizing a small number of 'canonical' long-dated options that will appeal to a broad set of investors.

Mean-square-optimal buy-and-hold portfolios. Table 2 reports the mean-square-optimal buy-and-hold portfolios for various levels of risk aversion and, for each risk-aversion parameter, for the number options $n$ varying from 0 to 5 . We use a larger number of options in this case to illustrate the fact that even with a larger number of options, a mean-squareoptimal portfolio need not come close in certainty equivalence to the optimal dynamic investment policy.

The first row of table 2's first panel corresponds to the optimal buy-and-hold portfolio with no options $(n=0)$, which is identical to the first row of table 1 's first panel. As the number of options $n$ is increased, the investor's welfare increases, so that for $n=5$, the certainty equivalent of the optimal 
Table 2. Mean-square-optimal buy-and-hold portfolios of stocks, bonds and $n$ European call options for CRRA utility under geometric Brownian motion stock-price dynamics with parameters $(\mu, \sigma)$ calibrated to match the following moments: $\mathrm{E}\left[\log \left(P_{t} / P_{t-1}\right)\right]=0.15$, $\operatorname{Var}\left[\log \left(P_{t} / P_{t-1}\right)\right]=0.04$. Other calibrated parameters include: riskless rate $r=5 \%$, initial stock price $P_{0}=\$ 50$, initial wealth $W_{0}=\$ 100000$, and time period $T=20$ years. 'RRA' denotes the coefficient of relative risk aversion, ' $\mathrm{CE}\left(W_{T}^{*}\right)$ ' denotes the certainty equivalent of the optimal dynamic stock/bond policy, and ' $\mathrm{CE}\left(V_{T}^{*}\right)$ ' denotes the certainty equivalent of the optimal buy-and-hold portfolio, reported as a percentage of $\mathrm{CE}\left(W_{T}^{*}\right)$.

\begin{tabular}{|c|c|c|c|c|c|c|c|c|c|}
\hline \multirow[b]{2}{*}{$n$} & \multirow[b]{2}{*}{$\begin{array}{l}\text { Options } \\
(\%)\end{array}$} & \multirow[b]{2}{*}{$\begin{array}{l}\text { Stock } \\
(\%)\end{array}$} & \multirow[b]{2}{*}{$\begin{array}{c}\mathrm{CE}\left(V_{T}^{*}\right) \\
(\%)\end{array}$} & \multirow[b]{2}{*}{$\begin{array}{l}\text { RMSE } \\
(\%)\end{array}$} & \multicolumn{5}{|c|}{ Option positions in optimal portfolio with $n$ options } \\
\hline & & & & & $\begin{array}{l}\text { Quantity } \\
\text { Strike (\$) }\end{array}$ & $\begin{array}{l}\text { Quantity } \\
\text { Strike (\$) }\end{array}$ & $\begin{array}{l}\text { Quantity } \\
\text { Strike (\$) }\end{array}$ & $\begin{array}{l}\text { Quantity } \\
\text { Strike (\$) }\end{array}$ & $\begin{array}{l}\text { Quantity } \\
\text { Strike (\$) }\end{array}$ \\
\hline 0 & 0.0 & 100.0 & 20.2 & $\begin{array}{c}\mathrm{CE}\left(W_{T}^{*}\right. \\
3659.6\end{array}$ & $=\$ 9948433$ & $\mathrm{RRA}=1($ & Log utility) & & \\
\hline 1 & 0.2 & 99.8 & 20.4 & 2889.6 & $\begin{array}{r}29.0 \times 10^{-6} \\
14696\end{array}$ & & & & \\
\hline 2 & 62.9 & -4.0 & 10.2 & 2886.7 & $\begin{array}{r}331561 \\
1398\end{array}$ & $\begin{array}{r}28.3 \times 10^{-6} \\
14696\end{array}$ & & & \\
\hline 3 & 2.8 & 97.2 & 23.1 & 2870.6 & $\begin{array}{r}2431277 \\
5388\end{array}$ & $\begin{array}{r}-68.2 \times 10^{-6} \\
14363\end{array}$ & $\begin{array}{r}94.7 \times 10^{-6} \\
14696\end{array}$ & & \\
\hline 4 & 8.0 & 92.0 & 28.1 & 2869.5 & $\begin{array}{r}943747 \\
3393\end{array}$ & $\begin{array}{r}2987657 \\
8712\end{array}$ & $\begin{array}{r}-85.9 \times 10^{-6} \\
14363\end{array}$ & $\begin{array}{r}111.0 \times 10^{-6} \\
14696\end{array}$ & \\
\hline 5 & 15.5 & 84.5 & 34.9 & 2869.3 & $\begin{array}{r}465463 \\
2396\end{array}$ & $\begin{array}{r}1415411 \\
6052\end{array}$ & $\begin{array}{r}2917259 \\
10374\end{array}$ & $\begin{array}{r}-92.0 \times 10^{-6} \\
14363\end{array}$ & $\begin{array}{r}116.2 \times 10^{-6} \\
14696\end{array}$ \\
\hline 0 & 0.0 & 100.0 & 81.9 & $\begin{array}{c}\mathrm{CE}\left(W_{T}^{*}\right. \\
206.2\end{array}$ & $=\$ 1644465$ & $\mathrm{RRA}=2$ & & & \\
\hline 1 & 0.8 & 99.2 & 83.4 & 57.2 & $\begin{array}{r}14846 \\
2063\end{array}$ & & & & \\
\hline 2 & 3.9 & 96.1 & 86.6 & 26.6 & $\begin{array}{l}9233 \\
1066\end{array}$ & $\begin{array}{r}15764 \\
9044\end{array}$ & & & \\
\hline 3 & 7.6 & 92.4 & 89.3 & 15.8 & $\begin{array}{r}6873 \\
733\end{array}$ & $\begin{array}{l}8120 \\
4390\end{array}$ & $\begin{array}{l}15063 \\
14696\end{array}$ & & \\
\hline 4 & 19.6 & 68.4 & 89.4 & 13.8 & $\begin{array}{r}4908 \\
401\end{array}$ & $\begin{array}{l}4815 \\
2063\end{array}$ & $\begin{array}{l}6273 \\
5388\end{array}$ & $\begin{array}{l}14315 \\
14696\end{array}$ & \\
\hline 5 & 17.5 & 82.5 & 94.0 & 13.3 & $\begin{array}{r}4342 \\
401\end{array}$ & $\begin{array}{l}3797 \\
1731\end{array}$ & $\begin{array}{l}3753 \\
3725\end{array}$ & $\begin{array}{l}4430 \\
6717\end{array}$ & $\begin{array}{l}13501 \\
14696\end{array}$ \\
\hline 0 & 0.0 & 24.4 & 84.7 & $\begin{array}{c}\mathrm{CE}\left(W_{T}^{*}\right. \\
28.3\end{array}$ & $=\$ 558453$ & $\mathrm{RRA}=5$ & & & \\
\hline 1 & -0.1 & 42.5 & 94.2 & 7.8 & $\begin{array}{r}-543 \\
1398\end{array}$ & & & & \\
\hline 2 & -0.6 & 50.8 & 96.6 & 3.6 & $\begin{array}{r}-554 \\
733\end{array}$ & $\begin{array}{l}-225 \\
4058\end{array}$ & & & \\
\hline 3 & -2.5 & 61.8 & 98.4 & 2.2 & $\begin{array}{r}-624 \\
401\end{array}$ & $\begin{array}{l}-246 \\
1731\end{array}$ & $\begin{array}{l}-159 \\
6385\end{array}$ & & \\
\hline 4 & -2.3 & 60.5 & 98.2 & 1.4 & $\begin{array}{r}-569 \\
401\end{array}$ & $\begin{array}{l}-218 \\
1398\end{array}$ & $\begin{array}{l}-134 \\
3725\end{array}$ & $\begin{array}{r}-110 \\
10374\end{array}$ & \\
\hline 5 & -2.1 & 59.0 & 98.1 & 1.0 & $\begin{array}{r}-500 \\
401\end{array}$ & $\begin{array}{l}-191 \\
1066\end{array}$ & $\begin{array}{l}-134 \\
2396\end{array}$ & $\begin{array}{l}-102 \\
5388\end{array}$ & $\begin{array}{r}-91 \\
13698\end{array}$ \\
\hline
\end{tabular}

buy-and-hold strategy is $34.9 \%$ of $\mathrm{CE}\left(W_{T}^{*}\right)$. Although this is a considerable improvement over the $n=0$ case, it is still quite far below the optimal dynamic strategy's certainty equivalent. This is not unexpected in light of the fact that we are minimizing mean-squared-error, not maximizing expected utility. As $n$ increases beyond 5, this approximation will improve eventually, but the optimization process becomes considerably more challenging for larger $n$. For example, the $n=15$ case involves $\left(\begin{array}{l}45 \\ 15\end{array}\right)=344867425584$ subproblems, and if each subproblem requires 0.01 seconds to solve, the overall optimization would take approximately 109.4 years to complete.

Unlike table 1 , in table 2 the certainty equivalents of the optimal buy-and-hold portfolio, $\operatorname{CE}\left(V_{T}^{*}\right)$, do not increase monotonically with the number of options $n$. For example, in the case of $\log$ utility $(\mathrm{RRA}=1), \mathrm{CE}\left(V_{T}^{*}\right)$ is $20.4 \%$ of $\mathrm{CE}\left(W_{T}^{*}\right)$ for $n=1$ option, but declines to $10.2 \%$ for $n=2$ options. This underscores the fact that we are minimizing 
Table 2. Continued.

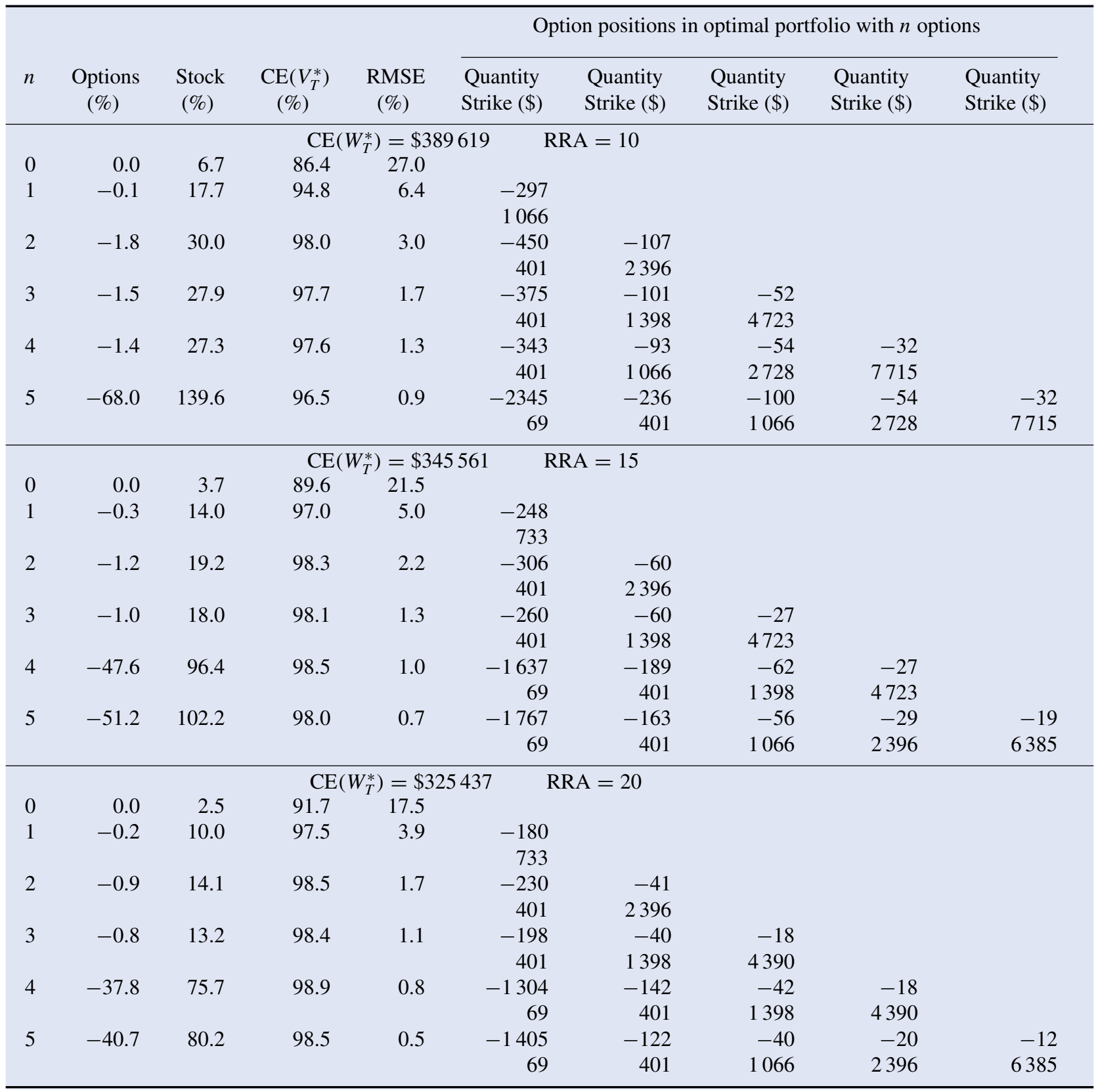

mean-squared-error in the optimal buy-and-hold portfolios of table 2, not maximizing expected utility. In fact, it is possible for a buy-and-hold portfolio to exhibit a small RMSE and a small certainty equivalent at the same time ${ }^{21}$. Therefore, while RMSE must decline monotonically with $n$, the certainty equivalents need not. Of course, as the number of options $n$ increases without bound, $\mathrm{CE}\left(V_{T}^{*}\right)$ will approach $\mathrm{CE}\left(W_{T}^{*}\right)$ eventually, even if not monotonically.

The option positions in the optimal buy-and-hold portfolios provide additional insight into the differences between maximizing expected utility and minimizing mean-

21 This typically occurs when the buy-and-hold strategy results in a final wealth $V_{T}^{*}$ that is close to zero over some interval of $P_{T}$. squared-error in constructing the optimal buy-and-hold portfolio. As $n$ increases from 0 to 1 in the first panel of table 2, the optimal buy-and-hold portfolio changes from $100 \%$ stocks to $99.8 \%$ stocks and $0.2 \%$ options, with a huge position (29.0 million) in the option with strike price \$14696. Given a current stock price of $\$ 50$, this option is obviously deeply out-of-the-money, hence its price is extremely close to zero, so close that 29.0 million options amount to only $0.2 \%$ of the investor's initial portfolio. Moreover, recall that these are 20-year options, hence a strike price of $\$ 14696$ should be compared not only with the current stock price but with the expected stock price at maturity, $P_{T}$. Recall that under geometric Brownian motion, the expected stock price 20 years 
into the future is $\$ 1498$. Therefore, even taking into account the expected appreciation in the stock over the next 20 years, the strikes are still extraordinarily high.

The $n=2$ case differs dramatically from the $n=1$ case. When given the opportunity to include 2 options in the buy-and-hold portfolio, the optimal weights become $62.9 \%$ in options, $-4.0 \%$ in the stock, and the remaining $41.1 \%$ in bonds. The optimal buy-and-hold portfolio involves shorting $\$ 4000$ of the stock and putting the proceeds, as well as the original $\$ 100000$, into bonds and options. The options component consists of two positions: 331561 options with a strike of $\$ 1398$, and 28.3 million options with a strike of $\$ 14696$. The latter position is similar to that of the $n=1$ case, and accounts for a relatively small part of the portfolio. The majority of the $69.2 \%$ allocated to options is due to the former position in options of a much lower strike price. The lower strike price implies a higher option price, hence the cost of 331561 of these options dwarfs the cost of 28.3 million of the higher-strike options. While this buy-and-hold portfolio is indeed optimal from a mean-squared-error criterion, the certainty equivalent reported in table 2 shows that the investor's welfare has actually declined by half, as compared to the $n=1$ case. Moreover, the RMSE declines only slightly, suggesting that we treat this case cautiously and with a certain degree of skepticism.

As the investor's risk-aversion parameter increases, table 2 shows that the optimal buy-and-hold portfolio performs considerably better in terms of certainty equivalence, in most cases attaining $90 \%$ or more of the certainty equivalent of the optimal dynamic strategy. For risk-aversion coefficients greater than 2, the RMSE of the buy-and-hold portfolio is less than $5 \%$ with only one or two options. The intuition for this pattern follows from the fact that investors with higher risk aversion invest a smaller proportion of their wealth in the stock market, hence their final wealth $W_{T}^{*}$ has lower variance which makes it easier to approximate $W_{T}^{*}$ with a buy-and-hold strategy.

The option positions in optimal buy-and-hold portfolios are also different for higher levels of risk aversion, consisting of fewer options and at lower strike prices. To see why, observe that for risk-aversion coefficients of 5 and greater, the optimal buy-and-hold portfolios with no options $(n=0)$ consist largely of bonds $(75.6 \%$ in bonds for RRA $=5,95.3 \%$ for RRA $=10$, $96.3 \%$ for $R R A=15$, and $97.5 \%$ for RRA $=20$ ). When options are allowed in the buy-and-hold portfolios, additional riskreduction possibilities become feasible and the optimization algorithm takes advantage of such opportunities. In particular, for risk-aversion levels of 5 and greater, the option positions are generally negative-the optimal buy-and-hold portfolios consist of selling options and investing the proceeds as well as the original $\$ 100000$ initial wealth in stocks and bonds. For example, the third panel of table 2 shows that with a riskaversion coefficient of 5, the optimal buy-and-hold portfolio with 5 options is $59.0 \%$ in stocks, $43.1 \%$ in bonds and $-2.1 \%$ in options, with short positions in all 5 options, and where the optimal strikes range from $\$ 401$ to $\$ 13698$. These results correspond well with those of table 1 , in which the optimal buy-and-hold portfolios of investors with higher risk-aversion coefficients contained hedged positions (long positions in the stock and short positions in options).

\subsection{The Ornstein-Uhlenbeck process}

To calibrate the parameters of the trending OrnsteinUhlenbeck process (4.8), we observe that the moments of the stationary distribution of $\left\{P_{t}\right\}$ are given by:

$$
\begin{aligned}
& \mathrm{E}\left[\log \left(P_{t} / P_{t-1}\right)\right]=\mu \\
& \operatorname{Var}\left[\log \left(P_{t} / P_{t-1}\right)\right]=\frac{\sigma^{2}}{\delta}(1-\exp (-\delta)) \\
& \operatorname{Corr}\left[\log \left(P_{t} / P_{t-1}\right), \log \left(P_{t-1} / P_{t-2}\right)\right]=-\frac{1}{2}(1-\exp (-\delta)) .
\end{aligned}
$$

Therefore, using the parameters in (5.5) and setting the firstorder autocorrelation coefficient equal to -0.05 uniquely calibrates the parameter vector $(\mu, \sigma, \delta)$. The distribution of $\log P_{T}$ implied by these parameters yields the following 45 possible strikes (in dollars) from which we select our $n$ options in the optimal buy-and-hold portfolio:

$\begin{array}{rrrrr}265 & 346 & 426 & 506 & 587 \\ 667 & 748 & 828 & 908 & 989 \\ 1069 & 1150 & 1230 & 1310 & 1391 \\ 1471 & 1552 & 1632 & 1712 & 1793 \\ 1873 & 1954 & 2034 & 2114 & 2195 \\ 2275 & 2356 & 2436 & 2517 & 2597 \\ 2677 & 2758 & 2838 & 2919 & 2999 \\ 3079 & 3160 & 3240 & 3321 & 3401 \\ 3481 & 3562 & 3642 & 3723 & 3803\end{array}$

Note that the distribution of possible strikes lies in a much narrower range in this case than in the geometric Brownian motion case of section 5.1: 265 to 3723 for the trending Ornstein-Uhlenbeck process versus 69 to 14363 for geometric Brownian motion. This is an implication of the meanreverting nature of the trending Ornstein-Uhlenbeck process, a stochastic process in which log-prices are stationary about a deterministic trend, in contrast to geometric Brownian motion in which log-prices are difference-stationary. In the former case, the variance of the log-price process is bounded as the horizon increases without bound, whereas in the latter case, the variance is proportional to the horizon, implying a wider range of strikes.

Recall from section 4.2 that because the optimal dynamic asset-allocation strategy is path-dependent under (4.8), the certainty equivalent of $V_{T}^{*}$ will not approach the certainty equivalent of $W_{T}^{*}$ as the number of options $n$ in the buy-andhold portfolio increases without bound. Indeed, there is an upper bound for $\operatorname{CE}\left(V_{T}^{*}\right)$, which is the certainty equivalent of the optimal buy-and-hold portfolio with an infinite number of options, $\operatorname{CE}\left(V_{T}^{\infty}\right)$, and for path-dependent dynamic portfolio strategies, $\operatorname{CE}\left(V_{T}^{\infty}\right)$ is strictly less than $\operatorname{CE}\left(W_{T}^{*}\right)$. In the case of the trending Ornstein-Uhlenbeck process (4.8) and CRRA preferences, we have an explicit expression for $V_{T}^{\infty}$ (see section 4.2), hence we can construct a mean-square optimal buy-and-hold portfolio where the benchmark is $V_{T}^{\infty}$, not $W_{T}^{*}$. 
Table 3. Utility-optimal buy-and-hold portfolios of stocks, bonds, and $n$ European call options for CRRA utility under a trending Ornstein-Uhlenbeck stock-price process where the parameters $(\sigma, \mu, \delta)$ have been calibrated to match the following moments: $\mathrm{E}\left[\log \left(P_{t} / P_{t-1}\right)\right]=0.15, \operatorname{Var}\left[\log \left(P_{t} / P_{t-1}\right)\right]=0.04, \operatorname{Corr}\left[\log \left(P_{t} / P_{t-1}\right), \log \left(P_{t-1} / P_{t-2}\right)\right]=-0.05$. Other calibrated parameters include: riskless rate $r=5 \%$, initial stock price $P_{0}=\$ 1$, initial wealth $W_{0}=\$ 100000$, and time period $T=20$ years. 'RRA' denotes the coefficient of relative risk aversion, ' $\mathrm{CE}\left(W_{T}^{*}\right)$ ' denotes the certainty equivalent of the optimal dynamic stock/bond policy, ' $\mathrm{CE}\left(V_{T}^{\infty}\right)$ ' denotes the certainty equivalent of the optimal buy-and-hold portfolio with a continuum of options, and ' $\mathrm{CE}\left(V_{T}^{*}\right)$ ' denotes the certainty equivalent of the optimal buy-and-hold portfolio with a finite number $n$ of options, reported as a percentage of $\operatorname{CE}\left(V_{T}^{\infty}\right)$.

\begin{tabular}{|c|c|c|c|c|c|c|c|}
\hline \multirow[b]{2}{*}{$n$} & \multirow[b]{2}{*}{$\begin{array}{c}\text { Options } \\
(\%)\end{array}$} & \multirow[b]{2}{*}{$\begin{array}{l}\text { Stock } \\
(\%)\end{array}$} & \multirow[b]{2}{*}{$\begin{array}{c}\mathrm{CE}\left(V_{T}^{*}\right) \\
(\%)\end{array}$} & \multirow[b]{2}{*}{$\begin{array}{l}\text { RMSE } \\
(\%)\end{array}$} & \multicolumn{3}{|c|}{$\begin{array}{l}\text { Option positions in optimal } \\
\text { portfolio with } n \text { options }\end{array}$} \\
\hline & & & & & $\begin{array}{l}\text { Quantity } \\
\text { Strike (\$) }\end{array}$ & $\begin{array}{l}\text { Quantity } \\
\text { Strike (\$) }\end{array}$ & $\begin{array}{l}\text { Quantity } \\
\text { Strike (\$) }\end{array}$ \\
\hline & \multicolumn{2}{|c|}{$\mathrm{CE}\left(W_{T}^{*}\right)=\$ 13162500$} & \multicolumn{2}{|c|}{$\mathrm{CE}\left(V_{T}^{\infty}\right)=\$ 12417350$} & \multirow{2}{*}{\multicolumn{2}{|c|}{ RRA $=1 \quad$ (Log utility) }} & \\
\hline 0 & 0.0 & 100.0 & 16.2 & 115.7 & & & \\
\hline 1 & 96.6 & 3.4 & 89.1 & 42.3 & $\begin{array}{r}24955 \\
426\end{array}$ & & \\
\hline 2 & 98.8 & 1.2 & 96.2 & 40.3 & $\begin{array}{r}6251 \\
346\end{array}$ & $\begin{array}{r}30824 \\
587\end{array}$ & \\
\hline \multirow[t]{2}{*}{3} & 98.8 & 1.2 & 97.8 & 12.6 & $\begin{array}{r}6047 \\
346\end{array}$ & $\begin{array}{r}33494 \\
587\end{array}$ & $\begin{array}{r}-39564 \\
1793\end{array}$ \\
\hline & \multicolumn{2}{|c|}{$\mathrm{CE}\left(W_{T}^{*}\right)=\$ 6166222$} & \multicolumn{2}{|c|}{$\mathrm{CE}\left(V_{T}^{\infty}\right)=\$ 5814196$} & \multicolumn{2}{|c|}{$\mathrm{RRA}=2$} & \\
\hline 0 & 0.0 & 100.0 & 31.3 & 87.5 & & & \\
\hline 1 & 83.9 & 16.1 & 89.0 & 29.1 & $\begin{array}{r}10204 \\
265\end{array}$ & & \\
\hline 2 & 83.0 & 17.0 & 90.5 & 34.2 & $\begin{array}{r}7822 \\
265\end{array}$ & $\begin{array}{r}4810 \\
426\end{array}$ & \\
\hline \multirow[t]{2}{*}{3} & 83.0 & 17.0 & 91.6 & 6.7 & $\begin{array}{r}8283 \\
265\end{array}$ & $\begin{array}{r}6623 \\
506\end{array}$ & $\begin{array}{r}-15246 \\
1391\end{array}$ \\
\hline & \multicolumn{2}{|c|}{$\mathrm{CE}\left(W_{T}^{*}\right)=\$ 2011701$} & \multicolumn{2}{|c|}{$\mathrm{CE}\left(V_{T}^{\infty}\right)=\$ 1874790$} & \multirow{2}{*}{\multicolumn{2}{|c|}{$\mathrm{RRA}=5$}} & \\
\hline 0 & 0.0 & 100.0 & 72.2 & 30.8 & & & \\
\hline 1 & 16.7 & 83.3 & 79.8 & 56.6 & $\begin{array}{r}2036 \\
265\end{array}$ & & \\
\hline 2 & 19.5 & 80.5 & 82.7 & 26.9 & $\begin{array}{r}5777 \\
265\end{array}$ & $\begin{array}{r}-5062 \\
346\end{array}$ & \\
\hline \multirow[t]{2}{*}{3} & 18.9 & 81.1 & 83.2 & 13.9 & $\begin{array}{r}5304 \\
265\end{array}$ & $\begin{array}{r}-4202 \\
346\end{array}$ & $\begin{array}{r}-2385 \\
989\end{array}$ \\
\hline & \multicolumn{2}{|c|}{$\mathrm{CE}\left(W_{T}^{*}\right)=\$ 957797$} & \multicolumn{2}{|c|}{$\mathrm{CE}\left(V_{T}^{\infty}\right)=\$ 900296$} & \multicolumn{2}{|c|}{$\mathrm{RRA}=10$} & \\
\hline 0 & 0.0 & 100.0 & 91.9 & 117.3 & & & \\
\hline 1 & -6.6 & 106.6 & 96.8 & 11.2 & $\begin{array}{r}-1712 \\
426\end{array}$ & & \\
\hline 2 & -7.0 & 107.0 & 97.1 & 3.8 & $\begin{array}{r}-1047 \\
346\end{array}$ & $\begin{array}{r}-951 \\
748\end{array}$ & \\
\hline 3 & -6.8 & 106.8 & 97.1 & 2.5 & $\begin{array}{r}-958 \\
346\end{array}$ & $\begin{array}{r}-641 \\
587\end{array}$ & $\begin{array}{l}-525 \\
1150\end{array}$ \\
\hline
\end{tabular}

Utility-optimal buy-and-hold portfolios. Table 3 summarizes the utility-optimal buy-and-hold portfolios for the same combination of risk-aversion parameters and number of options $n$ as in the geometric Brownian motion case of table 1 . The results for the panels with $\mathrm{RRA}=1,2,5$ were obtained by maximizing expected utility directly using a discretized distribution for $P_{T}$ (see section 3.1), and the results for the remaining three panels of table 3 were obtained by minimizing the utility-weighted mean-squared error (see section 3.3).

Note that for each level of risk aversion, the certainty equivalent $\mathrm{CE}\left(W_{T}^{*}\right)$ of the optimal dynamic strategy is considerably larger than that of the geometric Brownian motion case. The presence of predictability can be exploited by the investor and in doing so, his expected utility is increased dramatically, e.g. from a certainty equivalent of $\$ 9948433$ in the geometric Brownian motion case to $\$ 13162500$ in the Ornstein-Uhlenbeck case for log-utility. A more direct measure of the economic value of predictability can be obtained by considering the difference between the certainty equivalents of the optimal dynamic strategy and those of the optimal buy-and-hold portfolio with an infinite number of options. For a log-utility investor, this difference is $\$ 745150$ 
Table 3. Continued.

\begin{tabular}{|c|c|c|c|c|c|c|c|}
\hline \multirow[b]{2}{*}{$n$} & \multirow[b]{2}{*}{$\begin{array}{l}\text { Options } \\
(\%)\end{array}$} & \multirow[b]{2}{*}{$\begin{array}{l}\text { Stock } \\
(\%)\end{array}$} & \multirow[b]{2}{*}{$\begin{array}{c}\mathrm{CE}\left(V_{T}^{*}\right) \\
(\%)\end{array}$} & \multirow[b]{2}{*}{$\begin{array}{l}\text { RMSE } \\
(\%)\end{array}$} & \multicolumn{3}{|c|}{$\begin{array}{l}\text { Option positions in optimal } \\
\text { portfolio with } n \text { options }\end{array}$} \\
\hline & & & & & $\begin{array}{l}\text { Quantity } \\
\text { Strike (\$) }\end{array}$ & $\begin{array}{l}\text { Quantity } \\
\text { Strike (\$) }\end{array}$ & $\begin{array}{l}\text { Quantity } \\
\text { Strike (\$) }\end{array}$ \\
\hline & & $\mathrm{CE}\left(W_{T}^{*}\right)=$ & 834 & $\mathrm{CE}\left(V_{T}^{\infty}\right)=\$ 64765$ & $\mathrm{RR}$ & & \\
\hline 0 & 0.0 & 75.8 & 87.9 & 151.9 & & & \\
\hline 1 & -15.9 & 108.7 & 95.3 & 10.3 & $\begin{array}{r}-1937 \\
265\end{array}$ & & \\
\hline 2 & -15.5 & 108.1 & 95.2 & 2.0 & $\begin{array}{r}-1869 \\
265\end{array}$ & $\begin{array}{r}-285 \\
1150\end{array}$ & \\
\hline 3 & -16.9 & 110.2 & 95.7 & 3.9 & $\begin{array}{r}-2844 \\
265\end{array}$ & $\begin{array}{r}1435 \\
346\end{array}$ & $\begin{array}{r}-689 \\
587\end{array}$ \\
\hline & & $\operatorname{CE}\left(W_{T}^{*}\right)=$ & 880 & $\operatorname{CE}\left(V_{T}^{\infty}\right)=\$ 537074$ & $\mathrm{RR}$ & & \\
\hline 0 & 0.0 & 54.1 & 87.9 & 138.6 & & & \\
\hline 1 & -13.9 & 89.0 & 93.2 & 5.1 & $\begin{array}{r}-1686 \\
265\end{array}$ & & \\
\hline 2 & -15.5 & 91.7 & 93.7 & 11.6 & $\begin{array}{r}-2385 \\
265\end{array}$ & $\begin{array}{l}740 \\
346\end{array}$ & \\
\hline 3 & -15.7 & 92.0 & 93.8 & 4.0 & $\begin{array}{r}-2868 \\
265\end{array}$ & $\begin{array}{r}1753 \\
346\end{array}$ & $\begin{array}{r}-643 \\
506\end{array}$ \\
\hline
\end{tabular}

or $5.6 \%$ of $\mathrm{CE}\left(W_{T}^{*}\right)$, a significant amount. As the level of risk aversion increases, this difference declines in absolute termsless wealth is allocated to the risky asset, hence predictability has less of an impact-but is relatively stable as a percentage of $\mathrm{CE}\left(W_{T}^{*}\right)$, fluctuating between $4 \%$ and $6 \%$.

The most interesting feature of table 3 is that the certainty equivalents of the buy-and-hold portfolios do not approach $\mathrm{CE}\left(V_{T}^{\infty}\right)$ as quickly as the certainty equivalents of table 1 . This is most easily seen in the third panel (RRA $=5)$ in which the certainty equivalent of the optimal buy-and-hold portfolio with 3 options is only $83.2 \%$ of $\mathrm{CE}\left(V_{T}^{\infty}\right)$. However, as we remarked earlier, the data for this panel were computed by maximizing expected utility through a discretization of the distribution of $P_{T}$ using a grid of 4000 points. Because of the relatively high value of RRA, any interval in the support of $P_{T}$ where $W_{T}\left(P_{T}\right)$ is close to 0 will result in a large negative contribution to the certainty equivalent. We can address this issue by using a finer grid, but only at the expense of computational complexity ${ }^{22}$.

Another interesting feature of table 3 is that there is no investment in the bond in any of the buy-and-hold portfolios in the first four panels (RRA $=1,2,5,10)$. While this is not unexpected for low levels of risk aversion-such investors seek higher expected returns by the nature of their risk preferences - it is quite surprising for investors with RRA = 10. The intuition for this result comes from the fact that stock returns are predictable in this case, hence there is greater value to be gained from investing in stocks for each level of risk aversion. Alternatively, the predictability in stock returns

22 Since these numerical results are mainly for illustrative purposes, we have not endeavoured to optimize them within each panel. Instead, to ensure comparability across risk-aversion parameters and other specifications, we have attempted to hold fixed as many aspects of the optimization process as possible. make stocks less risky, ceteris paribus, hence even a risk-averse investor will hold a larger fraction of his wealth in stocks in this case.

As in tables 1 and 2, the optimal buy-and-hold portfolios for less risk-averse investors (RRA $=1,2,5$ ) are net positive in options, ranging from $98.8 \%$ when RRA $=1$ to $18.9 \%$ when $\mathrm{RRA}=5$, for $n=3$. However, unlike the geometric Brownian motion case, the optimal buy-and-hold portfolios do contain short positions in some options, even for these lower levels of risk aversion. For example, when RRA $=2$ and $n=3$, the optimal buy-and-hold portfolio consists of long positions in the \$265-strike and \$506-strike options, but a short position of 15246 options in the \$1391-strike option. For higher levels of risk aversion, the situation is reversed: the optimal buyand-hold portfolios are net negative in options, but they do contain long positions in certain options. For example, when RRA $=20$ and $n=3$, the optimal buy-and-hold portfolio consists of short positions in the \$265-strike and \$506-strike options, but a long position of 1753 options in the \$346-strike option.

These long and short positions underscore the complexity of an investor's ideal risk exposures, and may provide a useful benchmark for comparing different dynamic investment policies at a single point in time. In particular, it may be possible to re-interpret these option positions as classic spread trades, e.g. bull/bear and butterfly spreads, or combinations, e.g. strips, straps, straddles and strangles ${ }^{23}$. By doing so, we may be able to gain insight into the implicit bets that a particular dynamic asset-allocation strategy contains, and

${ }^{23}$ For this purpose, it may be useful to convert some of the call-option positions into their put-option equivalents using the put-call parity relation (see, for example, Cox and Rubinstein (1985)). 
Table 4. Mean-square-optimal buy-and-hold portfolios of stocks, bonds and $n$ European call options for CRRA utility under a trending Ornstein-Uhlenbeck stock-price process with parameters $(\sigma, \mu, \delta)$ calibrated to match the following moments: $\mathrm{E}\left[\log \left(P_{t} / P_{t-1}\right)\right]=0.15$, $\operatorname{Var}\left[\log \left(P_{t} / P_{t-1}\right)\right]=0.04, \operatorname{Corr}\left[\log \left(P_{t} / P_{t-1}\right), \log \left(P_{t-1} / P_{t-2}\right)\right]=-0.05$. Other calibrated parameters include: riskless rate $r=5 \%$, initial stock price $P_{0}=\$ 50$, initial wealth $W_{0}=\$ 100000$, and time period $T=20$ years. 'RRA' denotes the coefficient of relative risk aversion, ' $\mathrm{CE}\left(W_{T}^{*}\right)$ ' denotes the certainty equivalent of the optimal dynamic stock/bond policy, ' $\mathrm{CE}\left(V_{T}^{\infty}\right)$ ' denotes the certainty equivalent of the optimal buy-and-hold portfolio with a continuum of options, and ' $\mathrm{CE}\left(V_{T}^{*}\right)$ ' denotes the certainty equivalent of the optimal buy-and-hold portfolio with a finite number $n$ of options, reported as a percentage of $\operatorname{CE}\left(V_{T}^{\infty}\right)$.

\begin{tabular}{|c|c|c|c|c|c|c|c|c|c|}
\hline \multirow[b]{2}{*}{$n$} & \multirow[b]{2}{*}{$\begin{array}{l}\text { Options } \\
(\%)\end{array}$} & \multirow[b]{2}{*}{$\begin{array}{l}\text { Stock } \\
(\%)\end{array}$} & \multirow[b]{2}{*}{$\begin{array}{c}\mathrm{CE}\left(V_{T}^{*}\right) \\
(\%)\end{array}$} & \multirow[b]{2}{*}{$\begin{array}{c}\text { RMSE } \\
(\%)\end{array}$} & \multicolumn{5}{|c|}{ Option positions in optimal portfolio with $n$ options } \\
\hline & & & & & $\begin{array}{l}\text { Quantity } \\
\text { Strike (\$) }\end{array}$ & $\begin{array}{l}\text { Quantity } \\
\text { Strike (\$) }\end{array}$ & $\begin{array}{l}\text { Quantity } \\
\text { Strike (\$) }\end{array}$ & $\begin{array}{l}\text { Quantity } \\
\text { Strike (\$) }\end{array}$ & $\begin{array}{l}\text { Quantity } \\
\text { Strike (\$) }\end{array}$ \\
\hline & & \multicolumn{3}{|c|}{$\mathrm{CE}\left(W_{T}^{*}\right)=\$ 13162500$} & \multicolumn{2}{|c|}{$\mathrm{CE}\left(V_{T}^{\infty}\right)=\$ 12417350$} & \multicolumn{2}{|c|}{ RRA $=1$ (Log utility) } & \\
\hline 0 & 0.0 & $100.0^{1}$ & 16.2 & 115.7 & & & & & \\
\hline 1 & 91.7 & 8.3 & 87.4 & 37.5 & $\begin{array}{r}32697 \\
506\end{array}$ & & & & \\
\hline 2 & 86.8 & 13.2 & 81.3 & 9.3 & $\begin{array}{r}44428 \\
587\end{array}$ & $\begin{array}{r}-44691 \\
1712\end{array}$ & & & \\
\hline 3 & 87.0 & 13.0 & 81.5 & 6.3 & $\begin{array}{r}44694 \\
587\end{array}$ & $\begin{array}{r}-55819 \\
1793\end{array}$ & $\begin{array}{r}10865 \\
3803\end{array}$ & & \\
\hline 4 & 88.7 & -3.4 & 56.7 & 4.5 & $\begin{array}{r}45736 \\
587\end{array}$ & $\begin{array}{r}-33938 \\
1632\end{array}$ & $\begin{array}{r}-29561 \\
2195\end{array}$ & $\begin{array}{r}17831 \\
3803\end{array}$ & \\
\hline 5 & 90.2 & 9.8 & 56.7 & 2.7 & $\begin{array}{r}24169 \\
506\end{array}$ & $\begin{array}{r}24603 \\
748\end{array}$ & $\begin{array}{r}-32245 \\
1552\end{array}$ & $\begin{array}{r}-33388 \\
2114\end{array}$ & $\begin{array}{r}16665 \\
3803\end{array}$ \\
\hline & & $\mathrm{CE}\left(W_{T}^{*}\right.$ & $=\$ 6166222$ & & $\mathrm{CE}\left(V_{T}^{\infty}\right)=\$$ & 14196 & $\mathrm{RRA}=2$ & & \\
\hline 0 & 0.0 & 100.0 & 31.3 & 87.5 & & & & & \\
\hline 1 & 87.2 & 12.8 & 88.5 & 28.9 & $\begin{array}{r}10599 \\
265\end{array}$ & & & & \\
\hline 2 & 75.4 & 24.6 & 79.8 & 5.0 & $\begin{array}{r}14198 \\
346\end{array}$ & $\begin{array}{r}-14689 \\
1471\end{array}$ & & & \\
\hline 3 & 82.7 & -9.0 & 24.3 & 3.6 & $\begin{array}{r}15686 \\
346\end{array}$ & $\begin{array}{r}-6392 \\
1150\end{array}$ & $\begin{array}{r}-9114 \\
1632\end{array}$ & & \\
\hline 4 & 79.8 & 7.4 & 64.4 & 2.3 & $\begin{array}{r}15136 \\
346\end{array}$ & $\begin{array}{r}-8530 \\
1230\end{array}$ & $\begin{array}{r}-9152 \\
1873\end{array}$ & $\begin{array}{l}2399 \\
3803\end{array}$ & \\
\hline 5 & 82.1 & -5.9 & 37.4 & 1.6 & $\begin{array}{r}15582 \\
346\end{array}$ & $\begin{array}{r}-5987 \\
1150\end{array}$ & $\begin{array}{r}-6895 \\
1552\end{array}$ & $\begin{array}{r}-6095 \\
2195\end{array}$ & $\begin{array}{l}3515 \\
3803\end{array}$ \\
\hline & & $\mathrm{CE}\left(W_{T}^{*}\right.$ & $=\$ 2011701$ & & $\mathrm{CE}\left(V_{T}^{\infty}\right)=\$ 1$ & 4790 & $\mathrm{RRA}=5$ & & \\
\hline 0 & 0.0 & 100.0 & 72.2 & 30.8 & & & & & \\
\hline 1 & -0.2 & 100.2 & 72.4 & 26.8 & $\begin{array}{r}-2005 \\
1793\end{array}$ & & & & \\
\hline 2 & 17.1 & 82.9 & 81.4 & 6.3 & $\begin{array}{r}2421 \\
265\end{array}$ & $\begin{array}{r}-3647 \\
908\end{array}$ & & & \\
\hline 3 & 20.6 & 79.4 & 81.5 & 2.8 & $\begin{array}{r}3139 \\
265\end{array}$ & $\begin{array}{r}-3022 \\
667\end{array}$ & $\begin{array}{r}-1705 \\
1391\end{array}$ & & \\
\hline 4 & 26.4 & 73.6 & 80.5 & 1.8 & $\begin{array}{r}5151 \\
265\end{array}$ & $\begin{array}{r}-3730 \\
426\end{array}$ & $\begin{array}{r}-1731 \\
908\end{array}$ & $\begin{array}{r}-1162 \\
1552\end{array}$ & \\
\hline 5 & 29.0 & 71.0 & 79.9 & 1.4 & $\begin{array}{r}7665 \\
265\end{array}$ & $\begin{array}{r}-5731 \\
346\end{array}$ & $\begin{array}{r}-1481 \\
748\end{array}$ & $\begin{array}{r}-1063 \\
1150\end{array}$ & $\begin{array}{l}-810 \\
1632\end{array}$ \\
\hline
\end{tabular}

develop a standard lexicon for comparing those bets across investment policies.

Mean-square-optimal buy-and-hold portfolios. Table 4 summarizes the mean-square-optimal buy-and-hold portfolios for the same combination of strikes, risk-aversion parameters, and number of options $n$ as in table 3 . Table 4 shows that the RMSE of the optimal buy-and-hold portfolio declines rapidly. With only one or two options, the optimal buyand-hold portfolio is typically within $5 \%$ of the upper bound $\mathrm{CE}\left(V_{T}^{\infty}\right)$. For example, in the case where relative risk-aversion is 2, the RMSE of the optimal buy-and-hold portfolio with no options is $87.5 \%$; with 1 option, the RMSE declines to $28.9 \%$; and with 2 options, the RMSE is $5.0 \%$. With 5 options, the RMSE is less than $2.0 \%$ for all but the lowest level of risk aversion ( $\mathrm{RRA}=1$, for which the RMSE is $2.7 \%$ ). But as 
Table 4. Continued.

\begin{tabular}{|c|c|c|c|c|c|c|c|c|c|}
\hline \multirow[b]{2}{*}{$n$} & \multirow[b]{2}{*}{$\begin{array}{c}\text { Options } \\
(\%)\end{array}$} & \multirow[b]{2}{*}{$\begin{array}{l}\text { Stock } \\
(\%)\end{array}$} & \multirow[b]{2}{*}{$\begin{array}{c}\mathrm{CE}\left(V_{T}^{*}\right) \\
(\%)\end{array}$} & \multirow[b]{2}{*}{$\begin{array}{c}\text { RMSE } \\
(\%)\end{array}$} & \multicolumn{5}{|c|}{ Option positions in optimal portfolio with $n$ options } \\
\hline & & & & & $\begin{array}{l}\text { Quantity } \\
\text { Strike (\$) }\end{array}$ & $\begin{array}{l}\text { Quantity } \\
\text { Strike (\$) }\end{array}$ & $\begin{array}{l}\text { Quantity } \\
\text { Strike (\$) }\end{array}$ & $\begin{array}{l}\text { Quantity } \\
\text { Strike (\$) }\end{array}$ & $\begin{array}{l}\text { Quantity } \\
\text { Strike (\$) }\end{array}$ \\
\hline & & & \multicolumn{2}{|c|}{$\mathrm{CE}\left(W_{T}^{*}\right)=\$ 957797$} & \multirow{2}{*}{\multicolumn{2}{|c|}{$\mathrm{CE}\left(V_{T}^{\infty}\right)=\$ 900296$}} & \multicolumn{2}{|c|}{$\mathrm{RRA}=10$} & \\
\hline 0 & 0.0 & 39.0 & 67.9 & 28.4 & & & & & \\
\hline 1 & -1.7 & 74.7 & 86.5 & 4.5 & $\begin{array}{r}-1377 \\
748\end{array}$ & & & & \\
\hline 2 & -4.0 & 92.4 & 93.0 & 1.8 & $\begin{array}{r}-1367 \\
506\end{array}$ & $\begin{array}{r}-464 \\
1230\end{array}$ & & & \\
\hline 3 & -5.2 & 98.1 & 94.8 & 1.0 & $\begin{array}{r}-1200 \\
426\end{array}$ & $\begin{array}{r}-485 \\
828\end{array}$ & $\begin{array}{l}-277 \\
1471\end{array}$ & & \\
\hline 4 & -7.4 & 107.4 & 97.2 & 0.7 & $\begin{array}{r}-1166 \\
346\end{array}$ & $\begin{array}{r}-479 \\
667\end{array}$ & $\begin{array}{r}-288 \\
989\end{array}$ & $\begin{array}{l}-215 \\
1552\end{array}$ & \\
\hline 5 & -7.1 & 106.2 & 96.9 & 0.6 & $\begin{array}{r}-1061 \\
346\end{array}$ & $\begin{array}{r}-418 \\
587\end{array}$ & $\begin{array}{r}-278 \\
828\end{array}$ & $\begin{array}{l}-209 \\
1150\end{array}$ & $\begin{array}{r}-158 \\
1632\end{array}$ \\
\hline & & & $\mathrm{CE}\left(W_{T}^{*}\right)=$ & 681834 & $\mathrm{CE}\left(V_{T}^{\infty}\right)$ & $=\$ 647654$ & $\mathrm{RRA}=1$ & & \\
\hline 0 & 0.0 & 22.0 & 70.3 & 25.4 & & & & & \\
\hline 1 & -2.1 & 53.9 & 87.2 & 3.7 & $\begin{array}{r}-1003 \\
587\end{array}$ & & & & \\
\hline 2 & -4.0 & 64.4 & 90.7 & 1.4 & $\begin{array}{r}-1008 \\
426\end{array}$ & $\begin{array}{l}-259 \\
1069\end{array}$ & & & \\
\hline 3 & -6.1 & 72.9 & 93.0 & 0.8 & $\begin{array}{r}-1028 \\
346\end{array}$ & $\begin{array}{r}-283 \\
748\end{array}$ & $\begin{array}{l}-146 \\
1391\end{array}$ & & \\
\hline 4 & -5.9 & 71.8 & 92.8 & 0.5 & $\begin{array}{r}-974 \\
346\end{array}$ & $\begin{array}{r}-233 \\
667\end{array}$ & $\begin{array}{r}-136 \\
989\end{array}$ & $\begin{array}{r}-93 \\
1552\end{array}$ & \\
\hline 5 & -9.6 & 84.4 & 95.4 & 0.4 & $\begin{array}{r}-1037 \\
265\end{array}$ & $\begin{array}{r}-290 \\
506\end{array}$ & $\begin{array}{r}-168 \\
748\end{array}$ & $\begin{array}{l}-106 \\
1069\end{array}$ & $\begin{array}{r}-86 \\
1552\end{array}$ \\
\hline & & & $\operatorname{CE}\left(W_{T}^{*}\right)=$ & 560880 & $\operatorname{CE}\left(V_{T}^{\infty}\right.$ & $=\$ 537074$ & $\mathrm{RRA}=2$ & & \\
\hline 0 & 0.0 & 15.0 & 73.7 & 22.6 & & & & & \\
\hline 1 & -1.5 & 37.6 & 86.8 & 3.0 & $\begin{array}{r}-708 \\
587\end{array}$ & & & & \\
\hline 2 & -3.0 & 46.4 & 89.9 & 1.2 & $\begin{array}{r}-760 \\
426\end{array}$ & $\begin{array}{l}-155 \\
1069\end{array}$ & & & \\
\hline 3 & -4.7 & 53.6 & 91.8 & 0.6 & $\begin{array}{r}-808 \\
346\end{array}$ & $\begin{array}{r}-177 \\
748\end{array}$ & $\begin{array}{r}-86 \\
1391\end{array}$ & & \\
\hline 4 & -8.5 & 66.4 & 94.4 & 0.4 & $\begin{array}{r}-971 \\
265\end{array}$ & $\begin{array}{r}-191 \\
587\end{array}$ & $\begin{array}{r}-98 \\
908\end{array}$ & $\begin{array}{r}-67 \\
1471\end{array}$ & \\
\hline 5 & -7.8 & 63.9 & 94.1 & 0.3 & $\begin{array}{r}-866 \\
265\end{array}$ & $\begin{array}{r}-193 \\
506\end{array}$ & $\begin{array}{r}-105 \\
748\end{array}$ & $\begin{array}{r}-64 \\
1069\end{array}$ & $\begin{array}{r}-50 \\
1552\end{array}$ \\
\hline
\end{tabular}

in table 2 , the certainty equivalents of the optimal buy-andhold portfolio do not increase monotonically as the number of options increases, since we are optimizing mean-squarederror, not expected utility. For example, in the second panel $(\mathrm{RRA}=2)$ the certainty equivalent drops precipitously from $64.4 \%$ to $37.4 \%$ of the upper bound $\operatorname{CE}\left(V_{T}^{\infty}\right)$ as the number of options increases from 4 to 5 . However, for higher levels of risk aversion, the certainty equivalents do tend to increase with the number of options in the portfolio (and are guaranteed to converge to the upper bound $\mathrm{CE}\left(V_{T}^{\infty}\right)$ as $n$ increases without bound).

As risk aversion increases, the optimal buy-and-hold portfolios behave in a similar manner to those in table 2: options are used to hedge long positions in the stock. For risk-aversion levels of 10 or greater, all options positions are negative.

\subsection{A bivariate linear diffusion process}

We calibrate the parameters $\left(\kappa, \theta, \sigma_{1}, \sigma_{2}, \rho\right)$ of the bivariate linear diffusion (4.22) and (4.23) using the following values:

$$
\begin{aligned}
& \mathrm{E}\left[\log \left(P_{t} / P_{t-1}\right)\right]=0.15 \\
& \operatorname{Var}\left[\log \left(P_{t} / P_{t-1}\right)\right]=0.04 \\
& \operatorname{Var}\left[\mu_{t}\right]=0.025^{2} \\
& \operatorname{Corr}\left[\mu_{t}, \mu_{t-1}\right]=0.05 \\
& \rho=0 .
\end{aligned}
$$


The first two moments are calibrated with the same values as those in the geometric Brownian motion and trending Ornstein-Uhlenbeck cases. The value for the variance of $\mu_{t}$ implies a standard deviation of 250 basis points for the conditional mean $\mu_{t}$, and we assume that $\mu_{t}$ is only slightly autocorrelated over time, and not correlated at all with the Brownian motion driving prices. This calibration implies the following 45 possible strikes (in dollars) from which we select our $n$ options in the optimal buy-and-hold portfolio:

$\begin{array}{rrrrr}68 & 403 & 737 & 1071 & 1405 \\ 1739 & 2073 & 2407 & 2742 & 3076 \\ 3410 & 3744 & 4078 & 4412 & 4746 \\ 5081 & 5415 & 5749 & 6083 & 6417 \\ 6751 & 7085 & 7420 & 7754 & 8088 \\ 8422 & 8756 & 9090 & 9425 & 9759 \\ 10093 & 10427 & 10761 & 11095 & 11429 \\ 11764 & 12098 & 12432 & 12766 & 13100 \\ 13434 & 13768 & 14103 & 14437 & 14771\end{array}$

Note the similarity between the range of these strikes and that of geometric Brownian motion in section 5.1. This suggests that the economic properties of the bivariate linear diffusion process are close to those of geometric Brownian motion, which will be borne out by the optimal buy-and-hold portfolios described below.

As in the case of the trending Ornstein-Uhlenbeck process, under (4.22) and (4.23) the optimal dynamic assetallocation strategy is path-dependent. Therefore, we shall again use the upper bound $V_{T}^{\infty}$ as the benchmark in our mean-square-optimal buy-and-hold portfolio, and compare its certainty equivalent $\mathrm{CE}\left(V_{T}^{*}\right)$ to $\mathrm{CE}\left(V_{T}^{\infty}\right)$.

Utility-optimal buy-and-hold portfolios. Table 5 reports the optimal buy-and-hold portfolios under (4.22) and (4.23) for CRRA preferences with the same risk aversion levels as in tables 1-4. The results of the first two panels of table 5 were computed by maximizing expected utility according to section 3.1 and the results of the remaining panels were computed by minimizing utility-weighted mean-squared-error according to section 3.3.

Table 5 contains certain features in common with tables 1 and 3, but also exhibits some important differences. As in table 3 , the certainty equivalents of $V_{T}^{\infty}$ are lower than their counterparts for $W_{T}^{*}$, but in table 5 the gap declines monotonically as risk aversion increases. For log-utility, $\mathrm{CE}\left(V_{T}^{\infty}\right)$ is $15.5 \%$ less than $\mathrm{CE}\left(W_{T}^{*}\right)$, but this difference is only $7.5 \%$ when $\mathrm{RRA}=2,3.1 \%$ when $\mathrm{RRA}=5$, and $0.8 \%$ when $\mathrm{RRA}=20$. In contrast, the gap between $\operatorname{CE}\left(W_{T}^{*}\right)$ and $\operatorname{CE}\left(V_{T}^{\infty}\right)$ in table 3 is still $4.2 \%$ when RRA $=20$. This underscores the fact that the predictability of the bivariate linear diffusion is of a different form from that of the trending Ornstein-Uhlenbeck process.

Indeed, there are striking similarities between tables 5 and 1 , another indication that the terminal stock price $P_{T}$ and option prices corresponding to the two stochastic processes - as we have calibrated them-have much in common. However, note that the certainty equivalents in table 1 are relative to $\operatorname{CE}\left(W_{T}^{*}\right)$, not $\operatorname{CE}\left(V_{T}^{\infty}\right)$. Nevertheless, even the values of $\operatorname{CE}\left(V_{T}^{\infty}\right)$ in table 5 are extremely close to the values of $\operatorname{CE}\left(W_{T}^{*}\right)$ in table 1. This close correspondence suggests that for all practical purposes, the bivariate process (4.22) and (4.23) offers the same buy-and-hold investment opportunities to the investor as geometric Brownian motion.

Mean-square-optimal buy-and-hold portfolios. Table 6 reports the mean-square-optimal buy-and-hold portfolios under (4.22) and (4.23) for CRRA preferences with the same risk aversion levels as in table 5. These results match those in table 2 quite closely. Specifically, as in table 2 , the optimal buy-and-hold portfolio is a particularly poor approximation to both $W_{T}^{*}$ and $V_{T}^{\infty}$ in the log-utility case, with RMSE's greater than $3500 \%$, certainty equivalents $\operatorname{CE}\left(V_{T}^{*}\right)$ no greater than $35 \%$ of $\mathrm{CE}\left(V_{T}^{\infty}\right)$, and large swings in portfolio weights as $n$ is changed from 1 to 2 and from 2 to 3 . For higher levels of risk aversion, the optimal buy-and-hold portfolios in table 6 are remarkably close to those in table 2 in terms of portfolio weights, option positions, and certainty equivalents, providing further confirmation that the bivariate linear diffusion, calibrated according to (5.6), shares many of the same economic properties as geometric Brownian motion.

\section{Discussion}

For expositional purposes, we have made a number of simplifying assumptions, many of which can be relaxed at the expense of notational and computational complexity. In section 6.1, we consider some practical issues regarding the implementation of the optimal buy-and-hold portfolio. We discuss the advantages of using more complex derivative securities in section 6.2, and in section 6.3 we consider extending our analysis to other preferences and price processes. Finally, in section 6.4 we argue that the gap between $\operatorname{CE}\left(W_{T}^{*}\right)$ and $\operatorname{CE}\left(V_{T}^{\infty}\right)$ is a useful measure of the economic value of predictability, and discuss the role of taxes and transactions costs in interpreting the gap.

\subsection{Practical considerations}

An obvious prerequisite to any practical implementation of the optimal buy-and-hold portfolio proposed in section 3 is the existence of options with the appropriate maturity $T$ and strike prices $\left\{k_{i}^{*}\right\}$. These two issues-time-to-maturity and the set of available strikes-are related, since a longer time-tomaturity generally implies a greater dispersion for the optimal strikes (to accommodate the greater dispersion in the terminal stock-price distribution). For horizons less than one year, there are relatively liquid options on the S\&P 500 and other indexes, usually with a reasonable number of strikes above and below the spot price, hence the possibility of replacing certain dynamic investment strategies with an optimal buy-and-hold portfolio is plausible. However, for longer maturities such as the 20-year horizons proposed in the numerical examples of section 5, exchange-traded options do not exist.

This might seem to be a serious impediment to implementing the optimal buy-and-hold strategy for realistic investment horizons. However, we think there is hope for several reasons. First, longer-maturity index options are 
Table 5. Utility-optimal buy-and-hold portfolios of stocks, bonds and $n$ European call options for CRRA utility under a bivariate linear diffusion stock-price process with parameters $\left(\sigma_{1}, \sigma_{2}, \rho, \kappa, \theta\right)$ of the steady-state distribution calibrated to match the following moments: $\mathrm{E}\left[\log \left(P_{t} / P_{t-1}\right)\right]=0.15, \operatorname{Var}\left[\log \left(P_{t} / P_{t-1}\right)\right]=0.04, \operatorname{Var}\left[\mu_{t}\right]=0.025^{2}, \operatorname{Corr}\left[\mu_{t}, \mu_{t-1}\right]=0.05$, and $\rho=0$. Other calibrated parameters include: riskless rate $r=5 \%$, initial stock price $P_{0}=\$ 50$, initial wealth $W_{0}=\$ 100000$, and time period $T=20$ years. 'RRA' denotes the coefficient of relative risk aversion, ' $\mathrm{CE}\left(W_{T}^{*}\right)$ ' denotes the certainty equivalent of the optimal dynamic stock/bond policy, ' $\mathrm{CE}\left(V_{T}^{\infty}\right)$ ' denotes the certainty equivalent of the optimal buy-and-hold portfolio with a continuum of options, and ' $\mathrm{CE}\left(V_{T}^{*}\right)$ ' denotes the certainty equivalent of the optimal buy-and-hold portfolio with a finite number $n$ of options, reported as a percentage of $\operatorname{CE}\left(V_{T}^{\infty}\right)$.

\begin{tabular}{|c|c|c|c|c|c|c|c|}
\hline \multirow[b]{2}{*}{$n$} & \multirow[b]{2}{*}{$\begin{array}{l}\text { Options } \\
(\%)\end{array}$} & \multirow[b]{2}{*}{$\begin{array}{l}\text { Stock } \\
(\%)\end{array}$} & \multirow[b]{2}{*}{$\begin{array}{c}\mathrm{CE}\left(V_{T}^{*}\right) \\
(\%)\end{array}$} & \multirow[b]{2}{*}{$\begin{array}{l}\text { RMSE } \\
(\%)\end{array}$} & \multicolumn{3}{|c|}{$\begin{array}{l}\text { Option positions in optimal } \\
\text { portfolio with } n \text { options }\end{array}$} \\
\hline & & & & & $\begin{array}{l}\text { Quantity } \\
\text { Strike }(\$)\end{array}$ & $\begin{array}{l}\text { Quantity } \\
\text { Strike (\$) }\end{array}$ & $\begin{array}{l}\text { Quantity } \\
\text { Strike (\$) }\end{array}$ \\
\hline & \multicolumn{2}{|c|}{$\mathrm{CE}\left(W_{T}^{*}\right)=\$ 11861394$} & \multicolumn{2}{|c|}{$\mathrm{CE}\left(V_{T}^{\infty}\right)=\$ 10142498$} & \multirow{2}{*}{\multicolumn{2}{|c|}{ RRA $=1 \quad$ (Log utility) }} & \\
\hline 0 & 0.0 & 100.0 & 19.8 & 4346.6 & & & \\
\hline 1 & 60.3 & 39.7 & 68.2 & 4341.5 & $\begin{array}{r}56231 \\
737\end{array}$ & & \\
\hline 2 & 79.9 & 20.1 & 87.5 & 4332.2 & $\begin{array}{r}13577 \\
403\end{array}$ & $\begin{array}{r}151097 \\
1405\end{array}$ & \\
\hline \multirow[t]{2}{*}{3} & 99.3 & 0.7 & 91.9 & 4332.2 & $\begin{array}{r}786 \\
68\end{array}$ & $\begin{array}{r}12725 \\
403\end{array}$ & $\begin{array}{r}152096 \\
1405\end{array}$ \\
\hline & \multicolumn{2}{|c|}{$\mathrm{CE}\left(W_{T}^{*}\right)=\$ 1778906$} & \multicolumn{2}{|c|}{$\mathrm{CE}\left(V_{T}^{\infty}\right)=\$ 1645135$} & $\mathrm{RRA}=$ & & \\
\hline 0 & 0.0 & 100.0 & 81.8 & 214.7 & & & \\
\hline 1 & 64.6 & 35.4 & 94.4 & 197.4 & $\begin{array}{r}2258 \\
68\end{array}$ & & \\
\hline 2 & 58.0 & 42.0 & 99.2 & 155.4 & $\begin{array}{r}1600 \\
68\end{array}$ & $\begin{array}{r}3159 \\
403\end{array}$ & \\
\hline \multirow[t]{2}{*}{3} & 58.2 & 41.8 & 99.4 & 106.3 & $\begin{array}{r}1624 \\
68\end{array}$ & $\begin{array}{r}2811 \\
403\end{array}$ & $\begin{array}{l}4379 \\
1405\end{array}$ \\
\hline & \multicolumn{2}{|c|}{$\mathrm{CE}\left(W_{T}^{*}\right)=\$ 575004$} & \multicolumn{2}{|c|}{$\mathrm{CE}\left(V_{T}^{\infty}\right)=\$ 557315$} & $\mathrm{RRA}=$ & & \\
\hline 0 & 0.0 & 61.8 & 97.4 & 141.8 & & & \\
\hline 1 & -45.9 & 131.2 & 99.1 & 103.0 & $\begin{array}{r}-1604 \\
68\end{array}$ & & \\
\hline 2 & -36.7 & 119.8 & 99.8 & 35.4 & $\begin{array}{r}-1201 \\
68\end{array}$ & $\begin{array}{r}-595 \\
403\end{array}$ & \\
\hline \multirow[t]{2}{*}{3} & -36.8 & 120.0 & 99.8 & 14.8 & $\begin{array}{r}-1207 \\
68\end{array}$ & $\begin{array}{r}-568 \\
403\end{array}$ & $\begin{array}{r}-192 \\
1405\end{array}$ \\
\hline & \multicolumn{2}{|c|}{$\mathrm{CE}\left(W_{T}^{*}\right)=\$ 395205$} & \multicolumn{2}{|c|}{$\mathrm{CE}\left(V_{T}^{\infty}\right)=\$ 389080$} & \multicolumn{2}{|c|}{$\mathrm{RRA}=10$} & \\
\hline 0 & 0.0 & 26.5 & 96.7 & 154.7 & & & \\
\hline 1 & -46.8 & 101.5 & 98.9 & 105.1 & $\begin{array}{r}-1635 \\
68\end{array}$ & & \\
\hline 2 & -37.3 & 89.5 & 99.7 & 25.3 & $\begin{array}{r}-1250 \\
68\end{array}$ & $\begin{array}{r}-386 \\
403\end{array}$ & \\
\hline 3 & -37.4 & 89.6 & 99.7 & 6.1 & $\begin{array}{r}-1254 \\
68\end{array}$ & $\begin{array}{r}-376 \\
403\end{array}$ & $\begin{array}{r}-90 \\
1739\end{array}$ \\
\hline
\end{tabular}

always available through custom OTC derivatives contracts, although this is admittedly a very expensive alternative. Second, the scarcity of longer-maturity contracts is a reflection of existing demand-if optimal buy-and-hold portfolios become popular, this will create new demand for such contracts, leading to increased supply. Recent legislative debate regarding the privatization of the US social security system suggests the possibility of a huge increase in demand for such products and services. Third, insurance companies now provide various policies that have similar features to long-dated options, e.g. annuities with call and put features, contingent life-insurance policies etc, hence they may be a natural supplier of optimal buy-and-hold portfolios. And finally, an imperfect alternative to long-dated options is a carefully managed sequence of shorter-term options, and it may be possible to derive a dynamic trading strategy consisting of a sequence of overlapping options contracts that will yield the same investment profile as the optimal buy-and-hold strategy ${ }^{24}$. A dynamic trading strategy seems contrary to our

${ }^{24}$ See Bertsimas et al (2000b) for an example of how such a strategy might be derived. 
Table 5. Continued.

\begin{tabular}{|c|c|c|c|c|c|c|c|}
\hline \multirow[b]{2}{*}{$n$} & \multirow[b]{2}{*}{$\begin{array}{l}\text { Options } \\
(\%)\end{array}$} & \multirow[b]{2}{*}{$\begin{array}{l}\text { Stock } \\
(\%)\end{array}$} & \multirow[b]{2}{*}{$\begin{array}{l}\mathrm{CE}\left(V_{T}^{*}\right) \\
(\%)\end{array}$} & \multirow[b]{2}{*}{$\begin{array}{l}\text { RMSE } \\
(\%)\end{array}$} & \multicolumn{3}{|c|}{$\begin{array}{l}\text { Option positions in optimal } \\
\text { portfolio with } n \text { options }\end{array}$} \\
\hline & & & & & $\begin{array}{l}\text { Quantity } \\
\text { Strike (\$) }\end{array}$ & $\begin{array}{l}\text { Quantity } \\
\text { Strike (\$) }\end{array}$ & $\begin{array}{l}\text { Quantity } \\
\text { Strike (\$) }\end{array}$ \\
\hline & & $\left.W_{T}^{*}\right)=$ & 828 & $\operatorname{CE}\left(V_{T}^{\infty}\right)=\$ 34521$ & & & \\
\hline 0 & 0.0 & 16.2 & 97.3 & 124.2 & & & \\
\hline 1 & -36.9 & 76.2 & 99.1 & 82.9 & $\begin{array}{r}-1288 \\
68\end{array}$ & & \\
\hline 2 & -29.5 & 66.8 & 99.8 & 17.6 & $\begin{array}{r}-994 \\
68\end{array}$ & $\begin{array}{r}-261 \\
403\end{array}$ & \\
\hline 3 & -29.5 & 66.8 & 99.8 & 4.3 & $\begin{array}{r}-996 \\
68\end{array}$ & $\begin{array}{r}-255 \\
403\end{array}$ & $\begin{array}{r}-49 \\
1739\end{array}$ \\
\hline & & $\left.W_{T}^{*}\right)=$ & 732 & $\mathrm{CE}\left(V_{T}^{\infty}\right)=\$ 32518$ & $\mathrm{RR}$ & & \\
\hline 0 & 0.0 & 11.6 & 97.7 & 101.2 & & & \\
\hline 1 & -29.8 & 60.3 & 99.3 & 67.1 & $\begin{array}{r}-1041 \\
68\end{array}$ & & \\
\hline 2 & -23.8 & 52.8 & 99.8 & 13.3 & $\begin{array}{r}-807 \\
68\end{array}$ & $\begin{array}{r}-196 \\
403\end{array}$ & \\
\hline 3 & -23.9 & 52.8 & 99.8 & 3.3 & $\begin{array}{r}-809 \\
68\end{array}$ & $\begin{array}{r}-191 \\
403\end{array}$ & $\begin{array}{r}-33 \\
1739\end{array}$ \\
\hline
\end{tabular}

motivation for constructing a buy-and-hold alternative to the standard optimal dynamic asset-allocation policy. However, the inclusion of a few well-chosen short-maturity options from time to time in an otherwise passive buy-and-hold portfolio might be a very cost-effective and efficient alternative to the optimal dynamic policy, and we are investigating this possibility in our current research program.

Another issue that arises in the practical implementation of the optimal buy-and-hold strategy is computational challenges associated with the optimization procedure. As discussed in section 5 , there are limits to the number of subproblems that can be handled in a reasonable amount of time, which imposes limits on the number of possible strikes that can be considered, as well as the number of options $n$ in the buy-and-hold portfolio. In our numerical examples, we have made no attempt to optimize our algorithm for numerical and computational efficiency, preferring instead to maintain consistency across examples to facilitate comparisons. For example, when solving for the optimal buy-and-hold portfolio with $n=1$ option, there was no need to limit ourselves to just 45 possible strikes. In fact, this problem can be solved very efficiently even if we were to consider several thousand possible strikes. In addition, by selecting the range of strikes as a function of the relative risk-aversion parameter, it is possible to obtain considerably better results than those of tables $1-6^{25}$. Therefore, the numerical results of section 5 should be taken

${ }^{25}$ Specifically, having selected the $N$ possible strikes, we solve the $\left(\begin{array}{l}N \\ n\end{array}\right)$ subproblems as described in section 5.1. Once this is completed, we use the strikes $\left\{\hat{k}_{i}\right\}$ from the subproblem with the best optimum to select another set of $N$ possible strikes. This new set of $N$ strikes spans a smaller interval than the original set, but still contains $\left\{\hat{k}_{i}\right\}$. We then solve another $\left(\begin{array}{l}N \\ n\end{array}\right)$ subproblems and select the best optimum as our solution, and denote the corresponding strikes as $\left\{k_{i}^{*}\right\}$. This two-stage procedure for determining the set of possible strikes often yields significant improvements in the objective function. as illustrative only, and not necessarily indicative of the best possible performance of the optimal buy-and-hold portfolios.

\subsection{Other derivative securities}

For simplicity, we have used only European call options in our buy-and-hold strategies. A natural extension is to include more complex derivatives, perhaps with path dependences such as knock-out or average-rate options. This extension may be especially relevant in the presence of predictability, since in such cases we cannot attain $\operatorname{CE}\left(W_{T}^{*}\right)$ with a buyand-hold strategy even if we include an infinite number of European options. In fact, the specific form of predictability may suggest a class of derivatives that are particularly suitable. For example, in the case of the trending Ornstein-Uhlenbeck process (4.8), it seems reasonable to conjecture that derivatives whose payoffs depend on

$$
\int_{0}^{T} h\left(\left|X_{t}-X_{0}-\mu t\right|\right) \mathrm{d} t
$$

for some function $h(\cdot)$ would be most useful for approximating $W_{T}^{*}$ in a buy-and-hold portfolio. This should be true more generally for other mean-reverting stock-price processes. On the other hand, if the stock-price process displays some type of persistence or 'momentum', a different class of derivatives might be more appropriate.

\subsection{Other preferences and price processes}

Although we have confined much of our analysis in sections 4 and 5 to the special cases of CRRA and CARA preferences under three specific price processes, we wish to emphasize that 
Table 6. Mean-square-optimal buy-and-hold portfolios of stocks, bonds, and $n$ European call options for CRRA utility under a bivariate linear diffusion stock-price process with parameters $\left(\sigma_{1}, \sigma_{2}, \rho, \kappa, \theta\right)$ of the steady-state distribution calibrated to match the following moments: $\mathrm{E}\left[\log \left(P_{t} / P_{t-1}\right)\right]=0.15, \operatorname{Var}\left[\log \left(P_{t} / P_{t-1}\right)\right]=0.04, \operatorname{Var}\left[\mu_{t}\right]=0.025^{2}, \operatorname{Corr}\left[\mu_{t}, \mu_{t-1}\right]=0.05$, and $\rho=0$. Other calibrated parameters include: riskless rate $r=5 \%$, initial stock price $P_{0}=\$ 50$, initial wealth $W_{0}=\$ 100000$, and time period $T=20$ years. 'RRA' denotes the coefficient of relative risk aversion, ' $\mathrm{CE}\left(W_{T}^{*}\right)$ ' denotes the certainty equivalent of the optimal dynamic stock/bond policy, ' $\mathrm{CE}\left(V_{T}^{\infty}\right)$ ' denotes the certainty equivalent of the optimal buy-and-hold portfolio with a continuum of options, and ' $\mathrm{CE}\left(V_{T}^{*}\right)$ ' denotes the certainty equivalent of the optimal buy-and-hold portfolio with a finite number $n$ of options, reported as a percentage of $\mathrm{CE}\left(V_{T}^{\infty}\right)$.

\begin{tabular}{|c|c|c|c|c|c|c|c|c|c|}
\hline \multirow[b]{2}{*}{$n$} & \multirow[b]{2}{*}{$\begin{array}{l}\text { Options } \\
\text { (\%) }\end{array}$} & \multirow[b]{2}{*}{$\begin{array}{l}\text { Stock } \\
(\%)\end{array}$} & \multirow[b]{2}{*}{$\begin{array}{c}\mathrm{CE}\left(V_{T}^{*}\right) \\
(\%)\end{array}$} & \multirow[b]{2}{*}{$\begin{array}{l}\text { RMSE } \\
(\%)\end{array}$} & \multicolumn{5}{|c|}{ Option positions in optimal portfolio with $n$ options } \\
\hline & & & & & $\begin{array}{l}\text { Quantity } \\
\text { Strike (\$) }\end{array}$ & $\begin{array}{l}\text { Quantity } \\
\text { Strike (\$) }\end{array}$ & $\begin{array}{l}\text { Quantity } \\
\text { Strike (\$) }\end{array}$ & $\begin{array}{l}\text { Quantity } \\
\text { Strike (\$) }\end{array}$ & $\begin{array}{l}\text { Quantity } \\
\text { Strike (\$) }\end{array}$ \\
\hline & & & $\left(W_{T}^{*}\right)=$ & 11861394 & $\mathrm{CE}\left(V_{T}^{\infty}\right.$ & $=\$ 10142498$ & $\mathrm{RRA}=1$ & (Log utility) & \\
\hline 0 & 0.0 & 100.0 & 19.8 & 4346.6 & & & & & \\
\hline 1 & 0.2 & 99.8 & 20.0 & 3579.8 & $\begin{array}{r}35.36 \times 10^{-6} \\
14771\end{array}$ & & & & \\
\hline 2 & 100.0 & 0.0 & 0.0 & 3578.5 & $\begin{array}{r}247608 \\
1071\end{array}$ & $\begin{array}{r}34.8 \times 10^{-6} \\
14771\end{array}$ & & & \\
\hline 3 & 2.8 & 97.2 & 22.7 & 3564.7 & $\begin{array}{r}2695502 \\
5415\end{array}$ & $\begin{array}{r}-75.6 \times 10^{-6} \\
14437\end{array}$ & $\begin{array}{r}108.2 \times 10^{-6} \\
14771\end{array}$ & & \\
\hline 4 & 8.1 & 91.9 & 27.7 & 3563.8 & $\begin{array}{r}1023256 \\
3410\end{array}$ & $\begin{array}{r}3412389 \\
8756\end{array}$ & $\begin{array}{r}-96.3 \times 10^{-6} \\
14437\end{array}$ & $\begin{array}{r}127.2 \times 10^{-6} \\
14771\end{array}$ & \\
\hline 5 & 15.6 & 84.4 & 34.5 & 3563.7 & $\begin{array}{r}497357 \\
2407\end{array}$ & $\begin{array}{r}1586801 \\
6083\end{array}$ & $\begin{array}{r}3353435 \\
10427\end{array}$ & $\begin{array}{r}-103.3 \times 10^{-6} \\
14437\end{array}$ & $\begin{array}{r}133.3 \times 10^{-6} \\
14771\end{array}$ \\
\hline & & & $\left(W_{T}^{*}\right)=$ & 1778906 & $\mathrm{CE}\left(V_{T}^{\infty}\right)$ & $=\$ 1645135$ & $\mathrm{RRA}=2$ & & \\
\hline 0 & 0.0 & 100.0 & 81.8 & 214.7 & & & & & \\
\hline 1 & 0.5 & 99.5 & 82.9 & 62.2 & $\begin{array}{r}16875 \\
2407\end{array}$ & & & & \\
\hline 2 & 2.0 & 98.0 & 85.0 & 29.3 & $\begin{array}{r}11060 \\
1405\end{array}$ & $\begin{array}{l}18392 \\
10761\end{array}$ & & & \\
\hline 3 & 7.6 & 92.4 & 89.3 & 17.9 & $\begin{array}{r}7084 \\
737\end{array}$ & $\begin{array}{l}8847 \\
4412\end{array}$ & $\begin{array}{l}17361 \\
14771\end{array}$ & & \\
\hline 4 & 19.8 & 66.3 & 88.7 & 16.0 & $\begin{array}{r}5044 \\
403\end{array}$ & $\begin{array}{l}5127 \\
2073\end{array}$ & $\begin{array}{l}6858 \\
5415\end{array}$ & $\begin{array}{l}16539 \\
14771\end{array}$ & \\
\hline 5 & 17.5 & 82.5 & 94.0 & 15.5 & $\begin{array}{r}4417 \\
403\end{array}$ & $\begin{array}{l}4021 \\
1739\end{array}$ & $\begin{array}{l}4093 \\
3744\end{array}$ & $\begin{array}{l}4828 \\
6751\end{array}$ & $\begin{array}{l}15662 \\
14771\end{array}$ \\
\hline & & & $\left(W_{T}^{*}\right)=$ & 575004 & $\operatorname{CE}\left(V_{T}^{\infty}\right.$ & $=\$ 557315$ & $\mathrm{RRA}=5$ & & \\
\hline 0 & 0.0 & 24.6 & 85.0 & 27.9 & & & & & \\
\hline 1 & -0.1 & 42.5 & 94.3 & 7.7 & $\begin{array}{l}-536 \\
1405\end{array}$ & & & & \\
\hline 2 & -0.6 & 50.6 & 96.6 & 3.5 & $\begin{array}{r}-546 \\
737\end{array}$ & $\begin{array}{l}-223 \\
4078\end{array}$ & & & \\
\hline 3 & -2.4 & 61.5 & 98.4 & 2.1 & $\begin{array}{r}-615 \\
403\end{array}$ & $\begin{array}{l}-243 \\
1739\end{array}$ & $\begin{array}{l}-158 \\
6417\end{array}$ & & \\
\hline 4 & -2.2 & 60.2 & 98.3 & 1.3 & $\begin{array}{r}-561 \\
403\end{array}$ & $\begin{array}{r}-215 \\
1405\end{array}$ & $\begin{array}{r}-133 \\
3744\end{array}$ & $\begin{array}{r}-109 \\
10427\end{array}$ & \\
\hline 5 & -2.0 & 58.8 & 98.1 & 1.0 & $\begin{array}{r}-493 \\
403\end{array}$ & $\begin{array}{r}-189 \\
1071\end{array}$ & $\begin{array}{l}-132 \\
2407\end{array}$ & $\begin{array}{l}-101 \\
5415\end{array}$ & $\begin{array}{r}-91 \\
13768\end{array}$ \\
\hline
\end{tabular}

the optimal buy-and-hold portfolio can be derived for many other preferences and price processes. For example, the class of hyperbolic absolute risk-aversion (HARA) preferences can be accommodated, as well as any price process for which the conditional state-price density can be computed. Even more general preferences and price processes are allowable at the expense of computational complexity. For example, for price processes that do not admit closed-form expressions for the conditional state-price densities, these can be estimated nonparametrically as in Aït-Sahalia and Lo (1998).

\subsection{The predictability gap}

As we have seen in sections 4.2 and 4.3 , in the presence of predictability in the stock-price process, buy-and-hold portfolios of stocks, bonds and European call options cannot 
Table 6. Continued.

\begin{tabular}{|c|c|c|c|c|c|c|c|c|c|}
\hline \multirow[b]{2}{*}{$n$} & \multirow[b]{2}{*}{$\begin{array}{c}\text { Options } \\
(\%)\end{array}$} & \multirow[b]{2}{*}{$\begin{array}{l}\text { Stock } \\
(\%)\end{array}$} & \multirow[b]{2}{*}{$\begin{array}{c}\mathrm{CE}\left(V_{T}^{*}\right) \\
(\%)\end{array}$} & \multirow[b]{2}{*}{$\begin{array}{l}\text { RMSE } \\
(\%)\end{array}$} & \multicolumn{5}{|c|}{ Option positions in optimal portfolio with $n$ options } \\
\hline & & & & & $\begin{array}{l}\text { Quantity } \\
\text { Strike (\$) }\end{array}$ & $\begin{array}{l}\text { Quantity } \\
\text { Strike (\$) }\end{array}$ & $\begin{array}{l}\text { Quantity } \\
\text { Strike (\$) }\end{array}$ & $\begin{array}{l}\text { Quantity } \\
\text { Strike (\$) }\end{array}$ & $\begin{array}{l}\text { Quantity } \\
\text { Strike (\$) }\end{array}$ \\
\hline & & & $\mathrm{CE}\left(W_{T}^{*}\right)=$ & 395204 & $\mathrm{CE}\left(V_{T}^{\infty}\right)$ & $=\$ 389080$ & $\mathrm{RRA}=$ & & \\
\hline 0 & 0.0 & 6.7 & 86.5 & 26.9 & & & & & \\
\hline 1 & -0.1 & 17.7 & 94.9 & 6.4 & $\begin{array}{r}-295 \\
1071\end{array}$ & & & & \\
\hline 2 & -1.7 & 29.8 & 98.0 & 3.0 & $\begin{array}{r}-446 \\
403\end{array}$ & $\begin{array}{r}-107 \\
2407\end{array}$ & & & \\
\hline 3 & -1.5 & 27.8 & 97.7 & 1.7 & $\begin{array}{r}-371 \\
403\end{array}$ & $\begin{array}{r}-101 \\
1405\end{array}$ & $\begin{array}{r}-53 \\
4746\end{array}$ & & \\
\hline 4 & -1.4 & 27.2 & 97.6 & 1.3 & $\begin{array}{r}-340 \\
403\end{array}$ & $\begin{array}{r}-93 \\
1071\end{array}$ & $\begin{array}{r}-54 \\
2742\end{array}$ & $\begin{array}{r}-32 \\
7754\end{array}$ & \\
\hline 5 & -68.4 & 140.1 & 96.4 & 0.9 & $\begin{array}{r}-2357 \\
68\end{array}$ & $\begin{array}{r}-235 \\
403\end{array}$ & $\begin{array}{l}-100 \\
1071\end{array}$ & $\begin{array}{r}-53 \\
2742\end{array}$ & $\begin{array}{r}-33 \\
7754\end{array}$ \\
\hline & & & $\mathrm{CE}\left(W_{T}^{*}\right)=$ & 348,828 & $\mathrm{CE}\left(V_{T}^{\infty}\right.$ & $=\$ 345214$ & $\mathrm{RRA}=$ & & \\
\hline 0 & 0.0 & 3.7 & 89.7 & 21.4 & & & & & \\
\hline 1 & -0.3 & 13.9 & 97.1 & 5.0 & $\begin{array}{r}-246 \\
737\end{array}$ & & & & \\
\hline 2 & -1.2 & 19.1 & 98.3 & 2.2 & $\begin{array}{r}-304 \\
403\end{array}$ & $\begin{array}{r}-60 \\
2407\end{array}$ & & & \\
\hline 3 & -1.0 & 17.9 & 98.1 & 1.3 & $\begin{array}{r}-257 \\
403\end{array}$ & $\begin{array}{r}-59 \\
1405\end{array}$ & $\begin{array}{r}-27 \\
4746\end{array}$ & & \\
\hline 4 & -47.8 & 96.7 & 98.5 & 1.0 & $\begin{array}{r}-1644 \\
68\end{array}$ & $\begin{array}{r}-188 \\
403\end{array}$ & $\begin{array}{r}-62 \\
1405\end{array}$ & $\begin{array}{r}-27 \\
4746\end{array}$ & \\
\hline 5 & -51.5 & 102.6 & 97.9 & 0.7 & $\begin{array}{r}-1776 \\
68\end{array}$ & $\begin{array}{r}-162 \\
403\end{array}$ & $\begin{array}{r}-56 \\
1071\end{array}$ & $\begin{array}{r}-29 \\
2407\end{array}$ & $\begin{array}{r}-19 \\
6417\end{array}$ \\
\hline & & & $\mathrm{CE}\left(W_{T}^{*}\right)=$ & 327732 & $\mathrm{CE}\left(V_{T}^{\infty}\right)$ & $=\$ 325182$ & $\mathrm{RRA}=$ & & \\
\hline 0 & 0.0 & 2.5 & 91.8 & 17.5 & & & & & \\
\hline 1 & -0.2 & 9.9 & 97.6 & 3.9 & $\begin{array}{r}-179 \\
737\end{array}$ & & & & \\
\hline 2 & -0.9 & 14.0 & 98.6 & 1.7 & $\begin{array}{r}-228 \\
403\end{array}$ & $\begin{array}{r}-41 \\
2407\end{array}$ & & & \\
\hline 3 & -0.8 & 13.2 & 98.4 & 1.1 & $\begin{array}{r}-197 \\
403\end{array}$ & $\begin{array}{r}-40 \\
1405\end{array}$ & $\begin{array}{r}-18 \\
4412\end{array}$ & & \\
\hline 4 & -38.2 & 76.2 & 98.9 & 0.8 & $\begin{array}{r}-1316 \\
68\end{array}$ & $\begin{array}{r}-140 \\
403\end{array}$ & $\begin{array}{r}-44 \\
1405\end{array}$ & $\begin{array}{r}-18 \\
4746\end{array}$ & \\
\hline 5 & -40.9 & 80.5 & 98.5 & 0.5 & $\begin{array}{r}-1411 \\
68\end{array}$ & $\begin{array}{r}-121 \\
403\end{array}$ & $\begin{array}{r}-40 \\
1071\end{array}$ & $\begin{array}{r}-20 \\
2407\end{array}$ & $\begin{array}{r}-12 \\
6417\end{array}$ \\
\hline
\end{tabular}

approximate $W_{T}^{*}$ arbitrarily well, even as the number of options increases without bound. We use the term 'predictability gap' to denote the difference between $\operatorname{CE}\left(W_{T}^{*}\right)$ and $\operatorname{CE}\left(V_{T}^{\infty}\right)$, which depends on the investor's preferences as well as the parameters of the stock-price process.

The natural question to ask is how significant is this predictability gap? Given that the end-of-period wealth $W_{T}^{*}$ of the optimal dynamic asset-allocation policy is generally unattainable due to transaction costs and other market frictions, $\mathrm{CE}\left(W_{T}^{*}\right)$ can be viewed as a theoretical upper bound on how well an investor can do. On the other hand, if $V_{T}^{\infty}$ is well approximated by an optimal buy-and-hold portfolio $V_{T}^{*}$ with just a few options, it is more likely to be attainable in practice given that only a few trades are required to establish the portfolio and there are few costs to bear thereafter. Therefore, if the predictability gap is small, the buy-and-hold portfolio may well be optimal even in the presence of predictable stock returns. To investigate this possibility, we must consider the impact of transaction costs on $\mathrm{CE}\left(W_{T}^{*}\right)$.

Most of the studies in the transaction costs literature ignore predictability, assuming independently and identically distributed (IID) returns instead ${ }^{26}$. Such studies may underestimate the impact of transaction costs because the

${ }^{26}$ For example, Magill and Constantinides (1976), Constantinides (1986), Davis and Norman (1990), Dumas and Luciano (1991) and Gennotte and Jung (1992) all assume IID return-generating processes. 
presence of predictability provides another motive for trade, i.e. time-varying investment opportunity sets. Therefore, we might expect transaction costs-as a percentage of initial wealth $W_{0}$ - to be higher if stock returns are predictable.

Balduzzi and Lynch (1999) do consider transaction costs in the case of predictability, computing the impact on an investor's expected utility when transaction costs exist but are ignored by the investor. They do not report the difference between the certainty equivalent of the optimal asset-allocation policy in an economy without transaction costs and the certainty equivalent of the optimal policy in an economy with transaction costs (though their framework should allow them to do so easily). They do mention, however, that '.. the presence of transaction costs ... decreases the utility cost of ignoring predictability'. This suggests that $\mathrm{CE}\left(W_{T}^{*}\right)$ might be reduced significantly, reducing the predictability gap and providing more compelling motivation for the optimal buyand-hold portfolio.

An even more compelling motivation for the optimal buy-and-hold portfolio is the presence of taxes. For taxable investors, $\mathrm{CE}\left(W_{T}^{*}\right)$ is reduced by the present value of the sequence of capital gains taxes that are generated by an optimal dynamic asset-allocation strategy. In contrast, all of the capital gains taxes are deferred until date $T$ in a buy-and-hold portfolio. Therefore, the economic value of predictability is likely to be even lower for taxable investors, and the optimal buy-and-hold portfolio that much more attractive.

\section{Conclusion}

In this paper, we compare optimal buy-and-hold portfolios of stocks, bonds and options to the standard optimal dynamic asset-allocation policies involving only stocks and bonds. Under certain conditions, buy-and-hold portfolios are excellent approximations - in terms of certainty equivalence and mean-squared-error of end-of-period wealth-to their dynamic counterparts, suggesting that in those cases, dynamic trading strategies may be 'automated' by simple buy-andhold portfolios with just a few options. Cases where the approximation breaks down are also of interest, since such situations highlight the importance of dynamic trading opportunities.

There are a number of extensions of this research that may be worth pursuing. The most obvious is to perform similar analyses for other stochastic processes and preferences, those that are more consistent with the empirical evidence. The main challenge in this case is, of course, tractability and computational complexity.

A more important extension is to consider approximating other dynamic investment strategies with buy-and-hold portfolios of derivatives. Although we focus on optimal dynamic asset-allocation strategies in this paper, there is no reason to confine our attention to such a narrow class of strategies. For example, deriving optimal buy-and-hold strategies to approximate dollar-cost averaging strategies or other popular dynamic investment strategies-strategies that need not be based on expected utility maximization-might be of considerably broader interest.
Finally, the composition of the optimal buy-and-hold portfolio provides an interesting summary of the risk exposures of the optimal dynamic asset-allocation policy that the buyand-hold portfolio approximates. By examining the payoff structure of the optimal buy-and-hold portfolio, and its sensitivities to various market factors and economic shocks, we can develop insights into the risks of dynamic investment policies using measures computed at a single point in time. We hope to explore these and other extensions in the near future.

\section{Acknowledgments}

This research was partially supported by the MIT Laboratory for Financial Engineering and the National Science Foundation (grant no SBR-9709976). We thank Michael Dempster, Doyne Farmer, Leonid Kogan, Jiang Wang and participants at the Boston University Derivative Securities Conference and the MathSoft Conference on Statistical Modeling and Computation in Finance for valuable discussions and comments.

\section{Appendix A}

In this appendix, we derive the optimal value function $J(\cdot)$ from the Hamilton-Jacobi-Bellman equation (4.10) for the trending and standard Ornstein-Uhlenbeck processes.

\section{Appendix A.1. Trending Ornstein-Uhlenbeck value function}

We present here the solution to the Hamilton-Jacobi-Bellman equation (4.10) of section 4.2. Recall that this equation is given by:

$$
\begin{aligned}
0= & \operatorname{Max}_{\omega_{t}}\left\{J_{t}+W_{t} J_{W}\left(r+\omega_{t}\left[-\delta\left(X_{t}-\mu t-X_{0}\right)\right.\right.\right. \\
& \left.\left.+\mu+\frac{1}{2} \sigma^{2}-r\right]\right)+J_{X}\left(-\delta\left(X_{t}-\mu t-X_{0}\right)+\mu\right) \\
& \left.+\frac{1}{2} \omega_{t}^{2} \sigma^{2} W_{t}^{2} J_{W W}+\frac{1}{2} \sigma^{2} J_{X X}+\sigma^{2} \omega_{t} W_{t} J_{X W}\right\} .
\end{aligned}
$$

Solving for $\omega_{t}$ and substituting back into (A.1) yields the following partial differential equation (PDE):

$$
\begin{aligned}
0= & J_{t} J_{W W}+\left[-\delta\left(X_{t}-\mu t-X_{0}\right)+\mu\right] J_{X} J_{W W} \\
& +r W J_{W} J_{W W}+\frac{\sigma^{2}}{2} J_{X X} J_{W W}-\frac{\sigma^{2}}{2} J_{X W}^{2} \\
& -\left(-\delta\left(X_{t}-\mu t-X_{0}\right)+\mu+\frac{\sigma^{2}}{2}-r\right) J_{W} J_{X W} \\
& -\frac{\left(-\delta\left(X_{t}-\mu t-X_{0}\right)+\mu+\frac{\sigma^{2}}{2}-r\right)^{2}}{2 \sigma^{2}} J_{W}^{2}
\end{aligned}
$$

subject to $J(W, X, T)=U(W)$. We solve this PDE by conjecturing that

$J(W, X, t)=U(W \exp [r(T-t)]) \exp \left(\alpha(t)+\beta(t) X+\zeta(t) X^{2}\right)$

where $\alpha(T)=\beta(T)=\zeta(T)=0$. Therefore solving the PDE reduces to solving three ordinary differential equations. We then solve these differential equations for $\alpha(t), \beta(t)$ and $\zeta(t)$. 


\section{CRRA utility}

For an investor with the CRRA utility function, $U(W)=$ $W^{\gamma} / \gamma$, it is only possible to solve explicitly for $\beta(t)$ and $\zeta(t)$. Solving for $\alpha(t)$ required evaluating a number of definite integrals for which there did not seem to be analytic solutions. These integrals are easy to solve numerically, however, and it is therefore possible to find a very good numerical solution to the value function, $J(W, X, t)$. We present here the solutions for $\beta(t)$ and $\zeta(t)$. Let

$$
\begin{array}{ll}
a=1+\sqrt{1-\gamma}, & b=1-\sqrt{1-\gamma}, \\
q=\frac{-2 \delta}{\sqrt{1-\gamma}}, & H=\frac{-\gamma \delta^{2} \mu}{\sigma^{2} \sqrt{1-\gamma}} \\
I=\frac{\left(2 r-\sigma^{2}\right) \gamma \delta}{2 \sigma^{2}}, & J=\frac{\gamma \delta\left(2 r-2 \mu-\sigma^{2}\right)}{2 \sigma^{2} \sqrt{1-\gamma}} \\
K=\frac{-\gamma \delta \mu}{\sigma^{2}} . &
\end{array}
$$

Then $\beta(t)$ and $\zeta(t)$ are given by:

$$
\begin{aligned}
\beta(t)= & \frac{\sqrt{1-\gamma}}{\delta(a-b \exp [q(T-t)])}[(H t+K+I+J) \\
& -(H t-K+J-I) \exp (q(T-t)) \\
& \left.-2(K+I) \exp \left(\frac{q(T-t)}{2}\right)\right] \\
\zeta(t)= & \frac{\gamma \delta}{2 \sigma^{2}}\left[\frac{1-\exp (q(T-t))}{a-b \exp (q(T-t))}\right] .
\end{aligned}
$$

\section{CARA utility}

For the CARA utility function, $U(W)=-\exp (-\gamma W) / \gamma$, $\alpha(t), \beta(t), \zeta(t)$ are:

$$
\begin{aligned}
& \alpha(t)=\frac{\Gamma_{1}\left(t^{3}-T^{3}\right)}{3}+\frac{\Gamma_{2}\left(t^{2}-T^{2}\right)}{2}+\Gamma_{3}(t-T) \\
& \beta(t)=\Delta_{1}\left(t^{2}-T^{2}\right)+\Delta_{2}(T-t) \\
& \zeta(t)=\frac{\delta^{2}(t-T)}{2 \sigma^{2}}
\end{aligned}
$$

where

$$
\begin{aligned}
\Delta_{1}= & \frac{\delta^{2}}{4}-\frac{r \delta^{2}}{2 \sigma^{2}}-\frac{\delta^{2} \mu}{2 \sigma^{2}} \\
\Delta_{2}= & \frac{\delta}{2 \sigma^{2}}\left(\delta \sigma^{2} T-2 r \delta T+2 \mu+\sigma^{2}-2 r\right) \\
\Gamma_{1}= & \frac{\delta^{2} \mu^{2}}{2 \sigma^{2}}+\left(\frac{\sigma^{2}}{2}-r\right) \Delta_{1} \\
\Gamma_{2}= & \frac{\delta \mu}{\sigma^{2}}\left(\mu-r+\frac{\sigma^{2}}{2}\right)-\left(\frac{\sigma^{2}}{2}-r\right) \Delta_{2}-\frac{\delta^{2}}{2} \\
\Gamma_{3}= & \frac{\left(\mu-r+\frac{\sigma^{2}}{2}\right)^{2}}{2 \sigma^{2}}+\Delta_{1} T^{2}\left(r-\frac{\sigma^{2}}{2}\right) \\
& -\Delta_{2} T\left(r-\frac{\sigma^{2}}{2}\right)+\frac{\delta^{2} T}{2} .
\end{aligned}
$$

\section{Appendix A.2. Non-trending Ornstein-Uhlenbeck value function}

Recall that $X_{t} \equiv \log P_{t}$ and let $X_{t}$ satisfy the following stochastic differential equation:

$$
\mathrm{d} X_{t}=-\delta\left(X_{t}-\alpha\right) \mathrm{d} t+\sigma \mathrm{d} B_{t}
$$

where $\alpha$ and $\delta$ are both positive. The solution to (A.14) is given by:

$$
X_{t}=\alpha+\exp (-\delta t)\left[X_{0}-\alpha\right]+\sigma \exp (-\delta t) \int_{0}^{t} \exp (\delta s) \mathrm{d} B_{s}
$$

and the corresponding Hamilton-Jacobi-Bellman equation is given by

$$
\begin{aligned}
0= & \operatorname{Max}_{\omega}\left[J_{t}+W J_{W}\left((1-\omega) r-\delta \omega(\log P-\alpha)+\frac{\omega \sigma^{2}}{2}\right)\right. \\
& +P J_{P}\left(\frac{\sigma^{2}}{2}-\gamma(\log P-\alpha)\right)+\frac{1}{2} W^{2} \sigma^{2} J_{W W} \omega^{2} \\
& \left.+\frac{1}{2} P^{2} \sigma^{2} J_{P P}+W P \sigma^{2} \omega J_{P W}\right] .
\end{aligned}
$$

We solve this PDE by conjecturing that the value function is of the form:

$J(W, X, t)=U(W \exp [r(T-t)]) \exp \left(\alpha(t)+\beta(t) X+\zeta(t) X^{2}\right)$

where $\alpha(T)=\beta(T)=\zeta(T)=0$.

\section{CRRA utility}

For $U(W)=W^{\gamma} / \gamma$, we have the following system of ODEs:

$\frac{\mathrm{d} \alpha}{\mathrm{d} t}=\frac{\gamma}{\gamma-1}\left[\frac{\sigma^{2}}{2 \delta} \beta^{2}+\frac{\Delta_{3}}{2} \beta+\frac{\Delta_{2}}{2 \sigma^{2}}-\sigma^{2} \zeta\right]$

$\frac{\mathrm{d} \beta}{\mathrm{d} t}=\left(2 \sigma^{2} \zeta-\delta\right) \frac{\beta}{\gamma-1}+\frac{\gamma}{\gamma-1}\left[\Delta_{3} \zeta+\frac{\Delta_{1}}{2 \sigma^{2}}\right]$

$\frac{\mathrm{d} \zeta}{\mathrm{d} t}=\frac{2 \sigma^{2}}{\gamma-1} \zeta^{2}-\frac{2 \delta}{\gamma-1} \zeta+\frac{\delta^{2} \gamma}{2 \sigma^{2}(\gamma-1)}$

where

$\Delta_{1}=2 r \delta-\sigma^{2} \delta-2 \alpha \delta^{2}$

$\Delta_{2}=\sigma^{4} / 4+\alpha^{2} \delta^{2}+r^{2}-r \sigma^{2}+\sigma^{2} \delta \alpha-2 r \delta \alpha$

$\Delta_{3}=\sigma^{2}-2 r+\frac{2 \alpha \delta}{\gamma}$

Then

$$
\begin{aligned}
\beta(t)= & \left(2\left(d_{1}+d_{2}\right)-d_{1}\left(\mathrm{e}^{s(T-t)}+\mathrm{e}^{-s(T-t)}\right)-d_{2}\left(a \mathrm{e}^{s(T-t)}\right.\right. \\
& \left.\left.+b \mathrm{e}^{-s(T-t)}\right)\right)\left(s\left(a \mathrm{e}^{s(T-t)}-b \mathrm{e}^{-s(T-t)}\right)\right)^{-1} \\
\zeta(t)= & \frac{\delta \gamma}{2 \sigma^{2}}\left[\frac{1-\mathrm{e}^{q(T-t)}}{a-b \mathrm{e}^{q(T-t)}}\right]
\end{aligned}
$$

where

$$
\begin{array}{llrl}
d_{1}=\frac{\gamma^{2} \Delta_{3} \delta}{2(\gamma-1) \sigma^{2}}, & d_{2} & =\frac{\gamma \Delta_{1}}{2(\gamma-1) \sigma^{2}} \\
a & =1+\sqrt{1-\gamma}, & b & =1-\sqrt{1-\gamma} \\
s & =\frac{\delta(a-\gamma)}{(1-\gamma) a}, & q & =\frac{-2 \delta}{\sqrt{1-\gamma}}
\end{array}
$$

To define $\alpha(t)$, let:

$$
\begin{aligned}
f_{1}=\frac{\sigma^{2}}{2(\gamma-1)}, & f_{2}=\frac{\gamma \Delta_{3}}{2(\gamma-1)} \\
f_{3}=\frac{\gamma \Delta_{2}}{2(\gamma-1) \sigma^{2}}, & \rho_{1}=\frac{2\left(d_{1}+d_{2}\right)}{s} \\
\rho_{2}=\frac{-\left(d_{1}+a d_{2}\right)}{s}, & \rho_{3}=\frac{-\left(d_{1}+b d_{2}\right)}{s}
\end{aligned}
$$


and

$$
\begin{aligned}
& I_{1}=\left[2 a s\left(a \mathrm{e}^{2 s(T-t)}-b\right)\right]^{-1} \\
& I_{2}=\frac{-1}{2 s}\left[\frac{1}{a^{2}} \log \left(\frac{a-b \mathrm{e}^{-2 s(T-t)}}{b \mathrm{e}^{-2 s(T-t)}}\right)\right. \\
& \left.-\frac{1}{a\left(a-b \mathrm{e}^{-2 s(T-t)}\right)}\right] \\
& I_{3}=\frac{-1}{2 s}\left[\frac{1}{b^{2}} \log \left(\frac{a \mathrm{e}^{2 s(T-t)}}{a \mathrm{e}^{2 s(T-t)}-b}\right)\right. \\
& \left.-\frac{1}{b\left(a \mathrm{e}^{2 s(T-t)}-b\right)}\right] \\
& I_{4}=\frac{1}{2 s}\left[\frac{\mathrm{e}^{s(T-t)}}{b\left(a \mathrm{e}^{2 s(T-t)}-b\right)}\right. \\
& \left.+\frac{1}{b \sqrt{-a b}} \tan ^{-1}\left(\sqrt{\frac{-a}{b}} \mathrm{e}^{s(T-t)}\right)\right] \\
& I_{5}=\frac{1}{2 s}\left[\frac{\mathrm{e}^{s(T-t)}}{a\left(a \mathrm{e}^{2 s(T-t)}-b\right)}\right. \\
& \left.-\frac{1}{a \sqrt{-a b}} \tan ^{-1}\left(\sqrt{\frac{-a}{b}} \mathrm{e}^{s(T-t)}\right)\right] \\
& I_{7}=\frac{-1}{s \sqrt{-a b}} \tan ^{-1}\left(\sqrt{\frac{-a}{b}} \mathrm{e}^{s(T-t)}\right) \\
& I_{6}=I_{1} \\
& I_{8}=\frac{-1}{2 a s} \log \left(a \mathrm{e}^{2 s(T-t)}-b\right) \\
& I_{9}=\frac{-1}{2 b s} \log \left(a-b \mathrm{e}^{-2 s(T-t)}\right) \\
& I_{10}=\frac{\delta \gamma}{2 \sigma^{2}}\left[\frac{1}{a q} \log \left(a \mathrm{e}^{-q(T-t)}-b\right)\right. \\
& \left.-\frac{1}{b q} \log \left(a-b \mathrm{e}^{q(T-t)}\right)\right]
\end{aligned}
$$

where the solution is of the form:

$J(W, X, t)$

$$
=U(W \exp [r(T-t)]) \exp \left(\alpha(t)+\beta(t) X+\zeta(t) X^{2}\right) .
$$

Then

$\alpha(t)$

$$
\begin{gathered}
=f_{1}\left[\rho_{1}^{2} I_{1}+\rho_{2}^{2} I_{2}+\rho_{3}^{2} I_{3}+2 \rho_{1} \rho_{2} I_{4}+2 \rho_{1} \rho_{3} I_{5}+2 \rho_{2} \rho_{3} I_{6}\right] \\
+f_{2}\left[\rho_{1} I_{7}+\rho_{2} I_{8}+\rho_{3} I_{9}\right]-\sigma^{2} I_{10}+f_{3} t+G
\end{gathered}
$$

where $G$ is the constant defined by the condition $\alpha(T)=0$.

\section{CARA utility}

The solution of (A.16) for CARA utility, $U(W)=$ $-\exp (-\gamma W) / \gamma$ is given by:

$$
\begin{aligned}
\alpha(t)= & \frac{\delta^{2}}{6 \sigma^{2}}\left(\frac{\sigma^{2}}{2}-r\right)^{2}(t-T)^{3} \\
& +\left[\frac{\Delta_{1}}{4 \sigma^{2}}\left(\frac{\sigma^{2}}{2}-r\right)-\frac{\delta^{2}}{4}\right](T-t)^{2}-\frac{\Delta_{2}}{2 \sigma^{2}}(T-t)
\end{aligned}
$$$$
\beta(t)=\frac{\delta^{2}}{2}\left(\frac{1}{2}-\frac{r}{\sigma^{2}}\right)(t-T)^{2}-\frac{\Delta_{1}}{2 \sigma^{2}}(T-t)
$$

$\zeta(t)=\frac{\delta^{2}}{2 \sigma^{2}}(t-T)$

\section{References}

Ait-Sahalia Y and Lo A 1998 Nonparametric estimation of state-price densities implicit in financial asset prices J. Finance 52 499-548

Aiyagari R 1994 Uninsured idiosyncratic risk and aggregate saving Q. J. Econo. 109 659-84

Aiyagari R and Gertler M 1991 Asset returns with transactions costs and uninsured individual risk J. Monetary Econ. 27 311-31

Arnott R and Fabozzi F 1992 Active Asset Allocation (Chicago, IL: Probus)

Avellaneda M and Paras A 1994 Dynamic hedging portfolios for Appl. Math. Finance 1 165-93

Balduzzi P and Lynch A 1999 Transaction costs and predictability: some utility cost calculations J. Financial Econ. 52 47-78

Bensaid B, Lesne J, Pages H and Scheinkman J 1992 Derivative asset pricing with transaction costs Math. Finance 2 63-86

Bertsekas D 1999 Nonlinear Programming (Belmont, MA: Athena Scientific)

Bertsimas D, Kogan L and Lo A 2000a When is time continuous? $J$. Financial Econ. $\mathbf{5 5}$

Bertsimas D, Kogan L and Lo A 2000b Hedging derivative securities and incomplete markets: an $\epsilon$-arbitrage approach Operations Research 173-204

Black F and Scholes M 1973 Pricing of options and corporate liabilities J. Political Economy 81 637-54

Bodie Z, Kane A and Marcus A 1999 Investments 4th edn (Boston, MA: Irwin/McGraw-Hill)

Bodie Z and Merton R 1995 Financial infrastructure and public policy: a functional perspective The Global Financial System: A Functional Perspective ed D Crane, K Froot, S Mason, A Perold, R Merton, Z Bodie, E Sirri and P Tufano (Boston, MA: Harvard Business School Press)

Boyle P and Vorst T 1992 Option replication in discrete time with transaction costs J. Finance 47 271-94

Breeden D 1979 An intertemporal capital pricing model with stochastic investment opportunities J. Financial Econ. 7 265-96

Carr P, Jin X and Madan D 2001 Optimal consumption and derivative investment rules in continuous time Finance and Stochastics at press

Carr P and Madan D 2000 Optimal positioning in derivative securities Quantitative Finance 1 19-37

Constantinides G 1986 Capital market equilibrium with transaction costs J. Political Economy 94 842-62

Cox J and Huang C 1989 Optimum consumption and portfolio policies when asset prices follow a diffusion process $J$. Economic Theory 49 33-83

Cox J and Ross S 1976 The valuation of options for alternative stochastic processes J. Financial Economics 3 145-66

Cox J and Rubinstein M 1985 Options Markets (Englewood Cliffs, NJ: Prentice-Hall)

Delbaen F and Schachermeyer W 1996 The variance optimal martingale measure for continuous processes Bernoulli 9 81-105

Davis M and Norman A 1990 Portfolio selection with transactions costs Math. Operations Research 15 676-713

Davis M, Panas V and Zariphopoulou T 1993 European option pricing with transaction costs SIAM J. Control Optimization 31 470-93

Duffie D 1996 Dynamic Asset Pricing Theory 2nd edn (Princeton, derivative securities in the presence of large transactions costs NJ: Princeton University Press) 
Duffie D 1987 Stochastic equilibria with incomplete financial markets J. Economic Theory $\mathbf{4 1} 405-16$

Duffie D and Huang C 1985 Implementing Arrow-Debreu equilibria by continuous trading of few long-lived securities Econometrica 53 1337-56

Duffie D and Huang C 1990 Optimal hedging and equilibrium in a dynamic futures market J. Econ. Dynamics Control 14 21-33

Duffie D and Shafer W 1985 Equilibrium in incomplete markets I: A basic model of generic existence J. Math. Econ. 14 285-300

Duffie D and Shafer W 1986 Equilibrium in incomplete markets II: Generic existence in stochastic economies J. Math. Econ. 15 199-216

Dumas B and Luciano E 1991 An exact solution to the portfolio choice problem under transactions costs J. Finance 46 577-95

Edirisinghe C, Naik V and Uppal R 1993 Optimal replication of options with transaction costs and trading restrictions $J$ Financial Quantitative Analysis 28 117-38

Evnine J and Henriksson R 1987 Asset allocation and options $J$. Portfolio Management 14 56-61

Föllmer H and Sonderman D 1986 Hedging of non-redundant contingent-claims Contributions to Mathematical Economics, in Honor of Gérard Debreu ed W Hildebrand and A Mas-Colell (Amsterdam: North-Holland)

Fourer R, Gay D and Kernighan B 1999 AMPL: A Modeling Language for Mathematical Programming (San Francisco, CA: Scientific)

Gennotte G and Jung A 1992 Commissions and asset allocation $J$. Portfolio Management 19 12-23

Goll T and Rueschendorf L 2000 Minimax and minimal distance martingale measures and their relationship to portfolio optimization Institut für Mathematische Stochastik, Universität Freiburg Working Paper

Grannan E and Swindle G 1996 Minimizing transaction costs of option hedging strategies Math. Finance 6 341-64

Harrison J and Kreps D 1979 Martingales and arbitrage in multiperiod securities markets J. Econ. Theory 20 381-408

$\mathrm{He} \mathrm{H}$ and Modest D 1995 Market frictions and consumption-based asset pricing J. Political Economy 103 94-117

$\mathrm{He} \mathrm{H}$ and Pearson N 1991 Consumption and portfolio policies with incomplete markets and short-sale constraints J. Econ. Theory $54259-304$

Heaton J and Lucas D 1992 The effects of incomplete insurance markets and trading costs in a consumption-based asset pricing model J. Econ. Dynamics Control 16 601-20

Heaton J and Lucas D 1996 Evaluating the effects of incomplete markets on risk sharing and asset pricing J. Political Economy 104 443-87

Henriksson R and Merton 1981 On market timing and investment performance II: Statistical procedures for evaluating forecasting skills J. Business 54 513-33

Henrotte P 1993 Transactions costs and duplication strategies Stanford University Working Paper

Hodges S and Neuberger A 1989 Optimal replication of contingent claims under transaction costs Rev. Futures Markets 8 222-39

Huang C 1985a Information structure and equilibrium asset prices J. Econ. Theory 53 33-71

Huang C 1985b Information structures and viable price systems $J$. Math. Econ. 14 215-40

Kallsen J 1999 A utility maximization approach to hedging in incomplete markets Math. Methods of Operations Res. 50 $321-38$

Kim T and Omberg E 1993 Dynamic nonmyopic portfolio behavior San Diego State University Working Paper
Kim T and Omberg E 1996 Dynamic nonmyopic portfolio behavior Rev. Financial Studies 9 141-61

Kramkov D and Schachermayer W 1999 A condition on the asymtotic elasticity of utility functions and optimal investment in incomplete markets Ann. Appl. Probability 9 904-50

Leland H 1985 Option pricing and replication with transaction costs J. Finance 40 1283-301

Lo A 2000 Risk management for hedge funds: an introduction and overview Unpublished manuscript

Lo A and Wang J 1995 Implementing option pricing models when asset returns are predictable J. Finance 50 87-129

Lucas D 1994 Asset pricing with undiversifiable income risk and short sales constraints: deepening the equity premium puzzle $J$. Monetary Econ. 34 325-41

Magill M and Constantinides G 1976 Portfolio selection with transactions costs J. Econ. Theory 13 245-63

Magill M and Quinzii M 1996 Theory of Incomplete Markets (Cambridge, MA: MIT Press)

Merton R 1969 Lifetime portfolio selection under uncertainty: the continuous-time case Rev. Econ. Statistics 51 247-57

Merton R 1971 Optimum consumption and portfolio rules in a continuous-time model J. Econ. Theory 3 373-413

Merton R 1973 Theory of rational option pricing Bell J. Econ. Management Science 4 141-83

Merton R 1981 On market timing and investment performance I: an equilibrium theory of value for market forecasts J. Business $\mathbf{5 4}$ 363-406

Merton R 1992 Continuous-Time Finance (Cambridge, MA: Blackwell)

Merton R 1995 Financial innovation and the management and regulation of financial institutions J. Banking Finance 19 461-81

Merton R 1997 On the role of the Wiener process in finance theory and practice: the case of replicating portfolios Proc. Sym. Pure Mathematics $60218-19$

Neuberger A 1994 Option replication with transaction costs: an exact solution for the pure jump process Advances in Futures and Options Research vol 7 ed D Chance and R Trippi (Greenwich, CT: JAI)

Samuelson P 1969 Lifetime portfolio selection by dynamic stochastic programming Rev. Econ. Statistics 51 239-46

Schäl M 1994 On quadratic cost criteria for option hedging Math. Operations Research 19 121-31

Schäl M 2000 Portfolio optimization and martingale measures Math. Finance 10 289-303

Scheinkman J and Weiss L 1986 Borrowing constraints and aggregate economic activitiy Econometrica $5423-45$

Schweizer M 1992 Mean-variance hedging for general claims Ann. Appl. Prob. 2 171-9

Schweizer M 1995 Variance-optimal hedging in discrete time Math. Operations Research 20 1-31

Schweizer M 1996 Approximation pricing and the variance-optimal martingale measure Ann. Appl. Prob. 24 206-36

Sharpe W 1987 Integrated asset allocation Financial Analysts J. 43 25-32

Telmer C 1993 Asset-pricing puzzles and incomplete markets $J$ Finance 48 1803-32

Toft K 1996 On the mean-variance tradeoff in option replication with transactions costs J. Financial Quantitative Analysis 31 233-63

Weil P 1992 Equilibrium asset prices with undiversifiable labor income risk J. Econ. Dynamics Control 16 769-90

Whalley E and Wilmott P 1994 Hedge with an edge Risk Number 7 